\title{
ORGANIZACIÓN DEL ESPACIO Y USO DE LOS RECURSOS NATURALES EN LA CONFORMACIÓN DE ALDEAS Y CAMPAMENTOS EN EL PERÍODO MEDIO EN LOS VALLES DE AZAPA, NORTE DE CHILE Y CAPLINA, SUR DEL PERÚ
}

\author{
ORGANIZATION OF SPACE AND USO OF NATURAL RESOURCES \\ IN THE CONFIGURATION OF VILLAGES AND CAMPS IN THE \\ MIDDLE PERIOD IN THE AZAPA VALLEY, NORTHERN CHILE AND \\ CAPLINA VALLEY, SOUTHERN PERU
}

Iván Muñoz Ovalle y Jesús Gordillo Begazo ${ }^{2}$

\begin{abstract}
Este artículo intenta desarrollar un análisis comparativo sobre las estrategias de organización espacial durante el período Medio (500-1.000 d.C.) en dos valles emplazados en la frontera entre Chile y Perú, Azapa y Caplina, respectivamente. Para el desarrollo de este estudio nos hemos valido de los datos obtenidos a través del registro de aldeas y campamentos, información de carácter habitacional fundamental para el entendimiento de la forma de organización del patrón de asentamiento de estas poblaciones aldeanas prehispánicas a partir del desarrollo agrícola. Los elementos analizados son: (a) los recursos hídricos; (b) organización de los espacios interiores y exteriores de los asentamientos a través del análisis de las áreas de actividad; (c) vinculación de los asentamientos con senderos, figuras rupestres e hitos geográficos y; (d) extensión de los asentamientos y características del espacio donde se establecieron.

Los resultados del análisis de los datos refleja en general procesos similares para ambos valles, sin embargo Azapa contó con la existencia de un asentamiento como la aldea de San Lorenzo, que sirvió como articulador de las aldeas dispersas a lo largo del valle, constituyéndose en un referente integrador, situación no verificada en Caplina, al no contar con un asentamiento de estas características.
\end{abstract}

Palabras claves: organización del espacio, recursos naturales, aldeas y campamentos, valle de Azapa, valle del Caplina, período Medio.

This article attempts to develop for the first time a comparative analysis of the spatial organization strategies during the middle period (AD 500-1000) in two valleys located in the border between Chile and Peru, Azapa and Caplina respectively. In order to develop this study, we have used data obtained through the register of villages and camps, essential housing information for the understanding of the forms of organization of the settlement patterns of these pre-Hispanic village populations since agricultural development. The elements analyzed are the following: (a) importance of water resources, $(b)$ organization of interior or exterior spaces of the settlements, through the analysis of areas of activity; (c) linking of settlements with trails, rock figures, and geographic milestones, $(d)$ extension of settlements and characteristics of the space where they settled; and (e) constructive systems through the analysis of the forms of facilities and materials used.

The results of the data analysis show generally similar processes for both valleys, however, Azapa had the existence of a settlement like the San Lorenzo Pukara, which served as articulator for the villages dispersed along the valley, becoming a unifying reference, situation not verified in Caplina, since there isn't a settlement of these characteristics.

Key words: Organization of space, natural resources, villages and camps, Azapa Valley, Caplina Valley, Middle Period.

En el extremo norte de Chile el cordón occidental de la cordillera de los Andes presenta dos sistemas fluviales, uno de carácter endorreico con escurrimiento hacia el este que nutre los lagos altiplánicos y otro exorreico cuyo desplazamiento se produce en sentido oeste, escurriendo hacia el océano Pacífico. En este último se presentan dos tipos de cursos fluviales, los de carácter permanente, que desembocan en el océano y los intermitentes que no logran alcanzar la línea base del Pacífico. A este último tipo corresponde el sistema hidrográfico del río San José, curso fluvial que da origen al valle de Azapa tras atravesar la sierra de Huaylillas y la quebrada de Azapa. Este río posee dos tributarios: río Seco y Ticnamar. El valle de Azapa se conforma por el sector bajo de la cuenca del río San José y

\footnotetext{
1 Departamento de Antropología, Universidad de Tarapacá, Arica, Chile, Casilla 6-D. imunoz@uta.cl

2 Proyecto de Investigación arqueológico MOQI, Universidad Privada de Tacna, Tacna, Perú.jpg1801@ hotmail.com
} 
abarca 3.300 km² (Crom 1988/1989; Keller 1946; Tapia 2014), unos $58 \mathrm{~km}$ de largo y con un ancho variable de $700 \mathrm{~m}$ y $2.200 \mathrm{~m}$ (González et al. 2013). En el sector bajo del valle de Azapa, desde el kilómetro 1 al 14, han sido hallados variados tipos de asentamientos humanos prehispánicos, emplazados preferentemente en las proximidades de las laderas aprovechando planos, terrazas fluviales y algunas cotas inferiores de ladera. Su ubicación se relaciona con la captación de los recursos que ofrecen los ecosistemas húmedos, distribuidos desde la desembocadura del río San José hasta la quebrada del Diablo. Una de las primeras descripciones de este espacio esta en Vázquez de Espinosa (1948 [1629]) quien señala la existencia de numerosos totorales, entre ellos Azapa Grande, Saucache, Pago de Gómez, Las Ánimas y en la desembocadura el celebrado totoral de Arica. Observa que a causa del desarrollo de estos ecosistemas húmedos surge una vegetación permanente y en torno a ellos asentamientos de grupos humanos que viven en tensión por los recursos de agua.

Por su parte, la cuenca hidrográfica del río Caplina se extiende desde las estribaciones meridionales de la cordillera del Barroso, hasta el océano Pacífico, con un área de $2.400 \mathrm{~km}^{2}$. Nace en la cordillera del Barroso a $5.800 \mathrm{msm}$ con la denominación de quebrada de Piscullani. A la altura de los sectores de Caplina y Tocuco su cauce es encañonado y rocoso, luego se ensancha cortado por sedimentos blandos de la formación Moquegua. Entre Pachía y Tacna el valle toma una forma subrectangular con un lecho aluvial casi plano. El cauce inferior se caracteriza por su ensanchamiento en forma de abanico, dando lugar a un gran cono aluvial. Sus aguas no llegan al mar. La característica geomorfológica del valle facilitó el desarrollo de una agricultura intensa de riego por gravedad, cuyo control de agua se realizaba en el sector de Tocuco (Pachía), siendo la principal fuente de recursos hídricos del río Caplina, complementado por las escorrentías de la quebrada de Palca. Es en los sectores alto y medio, particularmente las zonas de Para y Magollo (con mejor calidad de suelos), donde se han registrado la mayor cantidad de sitios arqueológicos del período Medio. Uhle (1919) y Gordillo (1997) señalan la existencia de sitios funerarios y domésticos ubicados en las laderas de los cerros Para y Magollo.

Investigaciones referidas al período Medio en Azapa ${ }^{1}$ (Dauelsberg 1972/1973; Focacci 1983;
Muñoz 2004a; entre otros) y en Caplina (Gordillo 1997; Uhle 1919) indican que la disponibilidad de recursos hídricos, tanto de vertientes como de ríos, fue de vital importancia para determinar los espacios de asentamiento y ocupación humana, la que al parecer estuvo organizada a través de nodos o enclaves que se distribuían a lo largo de los valles. Otros factores que influenciaron la concentración de poblaciones en estos espacios, fue la existencia de condiciones climáticas estables, una topografía accesible que facilitó la interconexión e intercambio con otros grupos, y el mantenimiento de estancias para la explotación y generación de recursos, entre otros. De lo anteriormente señalado, la pregunta planteada en este estudio gira en torno a la forma, distribución y utilización de los recursos naturales por parte de las poblaciones locales en Azapa y Caplina. Para tal efecto se describen detalladamente las características más relevantes en torno a la relación de asentamientos humanos, recursos naturales y vinculación con el entorno.

Cabe consignar la existencia de una asimetría importante en relación al número de investigaciones en Azapa versus Caplina. El primero ha sido objeto de un mayor número de trabajos sobre la problemática habitacional prehispánica en los últimos años, en el segundo en cambio, los estudios han sido escasos. No obstante esta situación, creemos importante integrar al Caplina en una discusión más amplia, dada la similitud en cuanto a la calidad del agua existente en los dos valles y su poblamiento humano. No obstante estas similitudes, una de las diferencias sería el nivel de influencia que cada valle habría recibido desde la costa sur peruana y el altiplano circumtiticaca, siendo estas más profundas en Caplina que en Azapa.

\section{Antecedentes}

Los estudios sobre asentamientos habitacionales durante el período Medio (500-1.000 d.C.) en los valles de Azapa y Caplina han sido escasos. Esto se debería a la falta de evidencias materiales asociadas a sitios de este período, los que en su mayoría habrían estado emplazados en sectores colindantes a lechos de río o faldeos de cerros, terrenos que han sufrido profundas alteraciones producto de la erosión fluvial y del avance agrícola a partir del período Colonial. Sin embargo, es posible mencionar para Azapa los estudios en el poblado de San Lorenzo (Az-11) (Muñoz 1982, 
1986, 2004a, 2004b; Muñoz y Focacci 1985; entre otros), donde se describen y analizan problemáticas como las áreas de actividad en el interior de los recintos habitacionales, sistemas constructivos, relaciones espaciales entre asentamientos, entre otros aspectos. Muñoz (2004a) hace referencia a la existencia de pisos de ocupación de carácter doméstico como Az-143 y Az-145, vinculados a pequeños campamentos que se distribuyeron a lo largo del valle 2 . Según los trabajos de Rivera (1983), Muñoz (1995-1996, 2004b) y Goldstein (2006), habrían dos razones que explican el bajo número de recintos con ocupación doméstica: (a) el recubrimiento de los asentamientos domésticos producto de la erosión eólica, propia de nuestros valles desérticos y; (b) las características constructivas de los recintos, ya que utilizaron materiales perecederos (caña y totora), lo que habría generado su rápida degradación, eliminando testimonios de la ocupación. No obstante, el asentamiento habitacional de San Lorenzo (Az-11) ha entregado mayores datos sobre la organización de un asentamiento prehispánico en el período Medio.

En cuanto a la distribución de sitios en Azapa, varios investigadores (Goldstein 1995-1996, 2000, 2006; Muñoz 1983, 1995-1996; Muñoz y Focacci 1985; Rivera 1983; entre otros) han señalado que durante este período, las poblaciones habrían ocupado los sectores medios, desde el kilómetro 5 al 17 de la carretera principal, concentrándose por sobre el plano aluvial rivereño, cerca de las vertientes ubicadas en los sectores de Las Riberas, Alto Ramírez y Saucache, señalando una marcada preferencia por las zonas con irrigación óptima para la agricultura. Estas observaciones acerca de la manera de utilización del paisaje, coincide con la lógica de la organización espacial observada para el período Formativo (1.000 a.C.-350 d.C.) por Muñoz y Zalaquett (2011).

Respecto del valle de Caplina, el catastro de sitios arqueológicos realizado por Gordillo (1993, 2000) presenta escasos registros de ocupación para el período Medio, enfatizando el uso de las tierras productivas del valle para la explotación agrícola y la presencia de material cerámico afiliado al período Tiwanaku V. Se señala que los asentamientos debieron ser de forma rectangular con paredes confeccionadas de quincha construidas sobre una plataforma de piedras (Vela 2002). Diferente a los recintos construidos con muros de quincha, es el sitio El Atajo, con registros habitacionales de plantas circulares, asociados a fogones y hornos, posiblemente para elaborar cerámica. Este sitio tiene fechas de $\mathrm{C}^{14}$, que lo vinculan al período Formativo y Medio. Según Gordillo (1997) correspondería a una aldea de agricultores y alfareros locales establecida en el valle durante el proceso agrícola aldeano.

En cuanto al orden ocupacional del espacio iniciado por las poblaciones del período Medio en Caplina, se relacionarían directamente con zonas de producción agrícola (sitios domésticos) y laderas del cerro (cementerios). Lo anterior manifiesta la evidente selectividad para ocupar terrenos -en zonas específicas- con fines agrícolas, esto los define como una sociedad de enclaves focalizados (Mujica et al. 1983:90). Actualmente el sitio C40 (ubicado en el sector de Magollo), estaría indicando la presencia de un sector doméstico, probablemente con casas de quincha y base de piedra, ubicadas en el fondo aluvial del valle dentro de espacios agrícolas. Por su parte, los sitios C13 y C14, que corresponden a cementerios con tumbas tipo fosa con una ocupación que llega hasta el período Intermedio Tardío (Chiribaya, Maytas, San Miguel, Pocoma y Gentilar), sustentarían la propuesta de la superposición de espacios para prácticas de enterramientos.

\section{La Problemática Social Vista a través de los Estudios de Asentamientos}

Para entender cómo se distribuyeron y organizaron los asentamientos prehispánicos del período Medio en Azapa y Caplina, uno de los caminos más útiles es el análisis de los sistemas de asentamientos que presenta Drennan (2008), señalando que corresponden al mecanismo para establecer las interrelaciones entre los asentamientos (contexto dinámico), permitiendo por lo tanto, entender las diversas interacciones que definen y constituyen las comunidades humanas a varias escalas. Visto de esta manera, el sitio arqueológico deja de ser importante por sí mismo; y cobran importancia los vínculos entre asentamientos; el área deja de estar "estática" en el tiempo, constituyéndose en un territorio dinámico y complejo. En el caso de los Andes, el análisis de sistemas de asentamiento regionales ha permitido percibir -de manera amplia- el perfil activo de las sociedades prehispánicas, vinculado a los aspectos políticos, económicos y sociales que subyacen en su estructura organizacional (Albarracín-Jordán y Mattews 1990; Hodder y Orton 1990; McAndrews et al. 1997; 
Mattews 2003; Korpisaari 2006; Sanhueza et al. 2007; Uribe et al. 2016).

Siguiendo las distintas experiencias de estudios de patrones de asentamiento en el norte de Chile y sur del Perú (Adán y Urbina et al. 2011; Aldenderfer 1993; Conrad 1993; Chacama 2004; Fernández y Muñoz 2015; Goldstein 1989, 1993; Gordillo 1993, 1997; Muñoz 1993, 2005, 2015; Muñoz y Chacama 2006; Niemeyer et al. 1972/1973; Urbina et al. 2011; Watanabe y Stanish 1990; Williams et al. 2001; entre otros), se observa una serie de análisis relacionados con el patrón del emplazamiento y con el espacio ocupado, tamaño, articulación interna de su espacio, función social, visibilidad, entre otros aspectos estudiados.

En el presente trabajo, a partir del estudio del sector bajo del valle de Azapa y el sector medio del Caplina, pretendemos conocer cómo se dieron las relaciones entre grupos humanos en cada valle, enfatizando la utilización de los recursos naturales en relación con los sistemas constructivos (Ledezma 2010; Roper 1979), las funciones de cada asentamiento, las relaciones de poder (o estrategias de negociación) si las hubo y la planificación de los espacios productivos (Schortman y Urban 1985; Urban et al. 2002).

En cuanto a la distribución y uso del espacio de la vivienda en los asentamientos de Azapa, fundamentalmente en el sitio de San Lorenzo, estas presentan una rica información tanto de los componentes estructurales como de las áreas de actividad de tipo doméstica; evidencias que ayudarán a reconstruir el espacio al interior y exterior de la vivienda. En el valle de Caplina, el estudio del sitio El Atajo (C66) permite visualizar varias áreas de actividad relacionadas con manufacturas, cocinas, alimentación y desechos orgánicos (Gordillo 1997).

\section{Los Asentamientos Habitacionales en los Valles de Azapa y Caplina}

Para el valle de Azapa, la información sobre asentamientos habitacionales del período Medio en décadas pasadas y los recientes estudios sobre patrones de asentamientos, donde destacan los trabajos de Rivera (1983), Muñoz (2015), Fernández y Muñoz (2015) entre otros, corresponden a: Az-3, Az-4, Az-5, Az-6, Az-11, Az-24, Az-29, Az-83, Az-115, Az-148 (Tabla 1). Para el valle de Caplina los registros de sitios corresponden a los realizados por Gordillo (1993, 1997), a través del proyecto Catastro Arqueológico de Tacna: C2, C10, C12, C13, C14, C40 y C66 (Tabla 2).

\section{Metodología}

Los datos fueron procesados de la siguiente manera:

(1) Agua y asentamientos. Se tabuló la información bibliográfica, reconociéndose los lugares de asentamientos: terrazas y faldeos de cerro, y la relación con las vertientes y recursos de agua de los ríos San José y Caplina.

(2) Organización de los espacios externos de los asentamientos y áreas de actividad en los recintos internos. La información fue procesada en tablas, describiendo las áreas que constituyen un campamento o aldea, en algunos casos como el poblado de San Lorenzo se describió la distribución interna en los recintos de las áreas de actividad.

(3) Vinculación de los asentamientos con senderos, figuras rupestres e hitos geográficos demarcatorios. Se trabajó con mapas de ubicación, tabla de sitios y su distancia con la costa, además de la descripción de senderos que se desplazan hacia la costa por ambas laderas.

(4) Extensión y características del espacio donde se asentaron las poblaciones. Esta información se procesó a través de mediciones de los asentamientos y su relación con los recursos naturales.

\section{Análisis y Discusión}

\section{(1) Agua y asentamientos}

El valle de Azapa. Los sitios estudiados en Azapa se asocian directamente a ecosistemas de valle bajo y litoral. En los 17 kilómetros que transcurren desde la quebrada del Diablo hasta la desembocadura del río San José, el relieve no presenta elementos disruptivos en la intercomunicación de los distintos asentamientos distribuidos a lo largo del valle; situación que habría permitido desarrollar una relación permanente de visualización y contactos entre comunidades. El dominio visual de los asentamientos, distribuidos a través de una cadena de nodos, pudo haber ayudado a definir ciertos hitos geográficos que formaron parte del 
espacio ceremonial. Por otro lado, es posible que este esquema permitiera, además el control de ciertos espacios con recursos naturales como las canteras, de las cuales se extrajeron materias primas como bloques de piedras utilizadas en la construcción de pircas en la arquitectura doméstica y funeraria, en los grabados de petroglifos y en la preparación de morteros para la molienda. En el caso de San Lorenzo (Az-11) se han observado evidencias del aprovechamiento de la piedra concentrados en su entorno como los afloramientos ignimbríticos del cerro San Lorenzo, así como el traslado de bolones desde la ladera vecina de Az-75 y de cantos rodados del cauce del río San José. Ejemplos similares son posibles de apreciar en la terraza de Alto Ramírez y cerro Sagrado (Az-18). En el primero, el recurso predominante es la caña y la totora, obtenidas ambas desde los ecosistemas húmedos de las vertientes de la Mita Chica y la Luna; en el segundo, la confección de paneles de geoglifos con clastos ignimbríticos obtenidos del mismo cerro donde se diseñaron las figuras. Situación similar a los geoglifos de Atoca (Az-20) y la Tropilla (Az-21).

Espacialmente se observa una relación entre la existencia de vertientes y la ubicación de asentamientos. Se ha constatado el asentamiento de grupos (sitios) del período Medio en los alrededores de vertientes, lo que sugeriría la planificación y construcción en estos "ojos de agua" constituyéndose en puntos neurálgicos donde se desarrolló la vida humana ${ }^{3}$. En ese sentido, con el registro exhaustivo de esta vinculación espacial entre las comunidades y vertientes, hemos definido cuatro nodos, a los que denominamos: Nodo A (cerro Blanco), Nodo B (quebrada del Diablo), Nodo C (Las Ánimas) y Nodo D (Pago de Gómez) (Figura 1).

En el Nodo B se registran los sitios: Az-3, Az-4, Az-5, Az-6, Az-11 y Az-115, vinculados con el complejo que conforman vertientes, acequias y humedales que se ubican en la confluencia de la quebrada del Diablo y el valle de Azapa a la altura del kilómetro 13. Es probable que desde estos humedales se distribuyera y transportara, mediante acequias, el recurso hídrico a los campos de cultivos, como se constata en la aldea de San Lorenzo (Az-11), donde han sido hallados segmentos de acequias/canales, implicando la existencia de una planificación de carácter hidráulica, conformada por una red de canales que pudieron responder a una política agrícola sectorizada en la quebrada del Diablo (Figura 2).
Otros ejemplos de esta naturaleza lo constituyen Az-6, que por su ubicación sobre la terraza Altos de San Miguel, habría recibido el agua mediante acequias desde bocatomas más al interior del valle, pero circunscrita al complejo de vertientes del sector; en el caso de Az-115, ubicado en el plano de la misma terraza, también es probable que haya estado conectado por redes de acequia que iban por el curso de las cotas de base de la terraza. Desde el punto de vista de la distribución de los componentes del asentamiento de Az-115, se puede inferir que el sector funerario y residencial se ubicó en cotas superiores, mientras que el área económica destinada a cultivos pudo estar a nivel de la caja de valle.

A diferencia de los asentamientos antes descritos, el complejo de San Lorenzo (Az-11) además de haber traído el agua por acequia desde la quebrada del Diablo, también pudo haber dispuesto de su propia vertiente, La Peña, detectada inmediatamente en las cotas de intersección de planos de valle y base del farellón que conforma el promontorio de San Lorenzo. Es posible que desde esta vertiente - $\mathrm{La}$ Peña- conectada con redes de acequia proveniente de vertientes vecinas como La Concepción, Pejerrey y el Socavón contribuyeran a alimentar áreas económicas de mayor extensión que incluyó el sector de las Maytas.

El asentamiento Az-148, ubicado en el Nodo $\mathrm{C}$, se vincula con el ecosistema denominado Las Ánimas, este comprende varias vertientes reconocidas como La Media Luna, La Mita Chica y El Gallito entre otras, y ocupa el ancho total entre la ladera norte y la ladera sur que correspondería a la terraza de Alto Ramírez, siendo dividido este complejo ecológico ambiental por el cauce del río San José. La aldea de Az-83 se orienta unos 100 $\mathrm{m}$ al interior de la quebrada seca de las Lloyllas y próxima al cauce de la quebrada del mismo nombre. Para este asentamiento Espoueys (1973) señala áreas destinadas al cultivo y un posible canal. $\mathrm{Su}$ existencia habría requerido tal vez de un sistema de irrigación permanente cuya captación de agua pudo estar en sectores altos del valle, probablemente de la quebrada del Diablo, su curso estaría en cotas inferiores de la topografía de la ladera sur, para luego adentrarse a la quebrada de las Lloyllas y conectarse con el asentamiento.

El sitio Az-24, ubicado en el Nodo D, utilizó los recursos naturales provenientes del complejo de vertientes del sector de Pago de Gómez, a 2 km al interior de la caja del valle. En este espacio se 


\begin{tabular}{|c|c|c|}
\hline 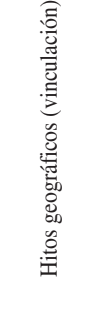 & 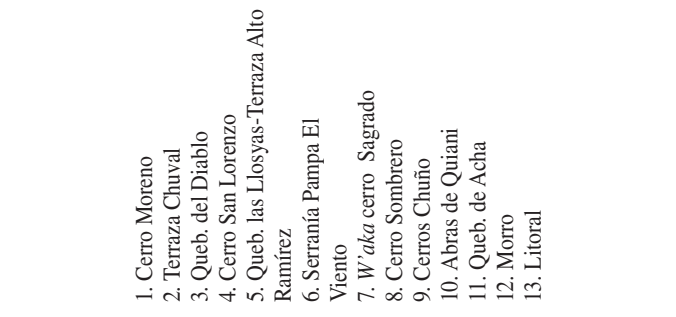 & \\
\hline 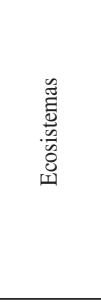 & 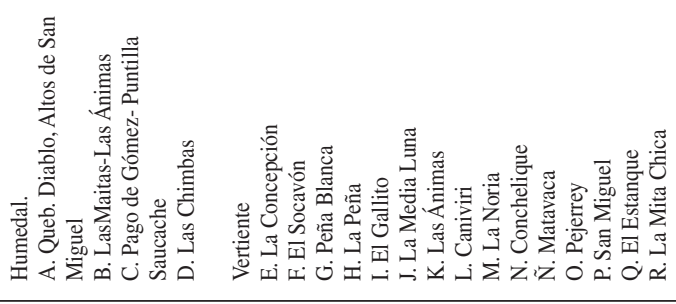 & \\
\hline \multirow{3}{*}{ 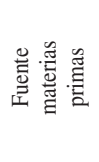 } & $\varangle+-0-\sigma \Xi-0=-0$ & \\
\hline & $0 \pi=00 \quad W 0$ & \\
\hline & $U \pi=-0-\sigma$ & \\
\hline \multirow{2}{*}{ 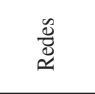 } & $n=\Xi-\pi \cdot-n+-0$ & \\
\hline & 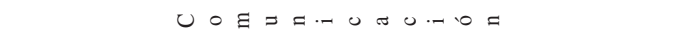 & \\
\hline \multirow{2}{*}{ 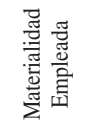 } & $-=0-\operatorname{sos}=-0 \pi$ & \\
\hline & $0-\cos \theta=-0 \pi$ & \\
\hline \multirow{11}{*}{ 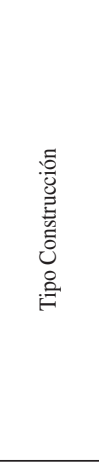 } & \multirow{6}{*}{$+00=0-000 \cdot-00$} & $\Xi=-0 \quad 20+-\Xi 0+H-$ \\
\hline & & $\pi 000$ \\
\hline & & $500 \pi-0 \equiv \pi$ \\
\hline & & $-0+H \pi-v=$ \\
\hline & & $000 .-1=0$ \\
\hline & & $n \cdot-0$ \\
\hline & \multirow{2}{*}{ w 00 O 0 O } & $0=-\cdots+>0$ \\
\hline & & $000000-\cdots+\cdots$ \\
\hline & $x-t=\pi-H=20$ is $\rightarrow+0$ & 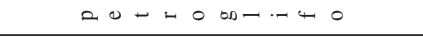 \\
\hline & & $\mu=\{0+a+\cdots$ \\
\hline & & $>-r>-\theta=0 \sigma$ \\
\hline \multirow{4}{*}{ 总 } & 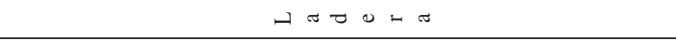 & \\
\hline & $2+0 \equiv 0=-0+\cdots 0$ & \\
\hline & $a-\pi=0>\pi--0$ & \\
\hline & $H \theta H+a n a$ & \\
\hline $\begin{array}{l}0 \\
0 \\
0 \\
z\end{array}$ & & \\
\hline$\stackrel{\mathscr{C}}{\mathscr{n}}$ & & \\
\hline
\end{tabular}




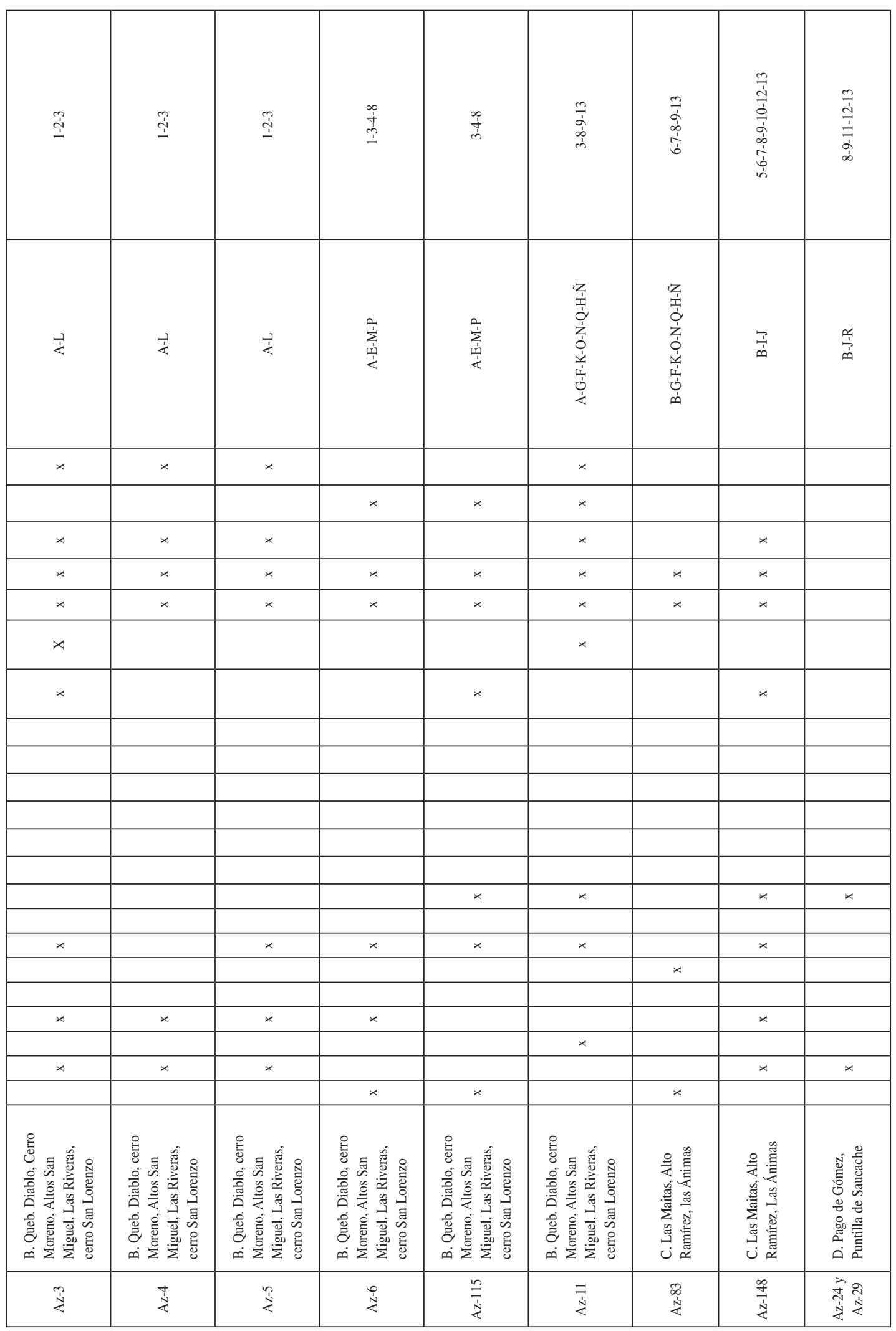




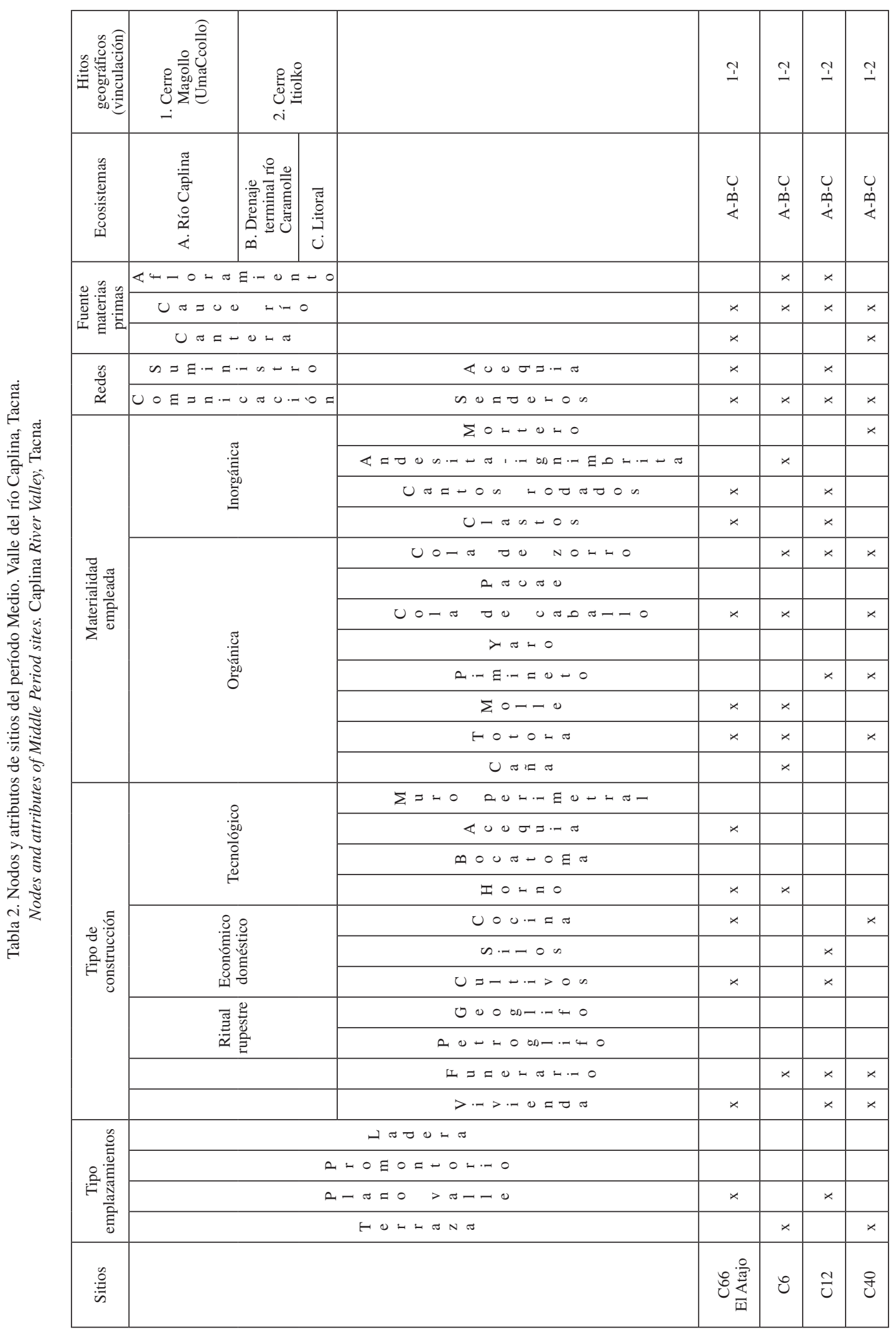




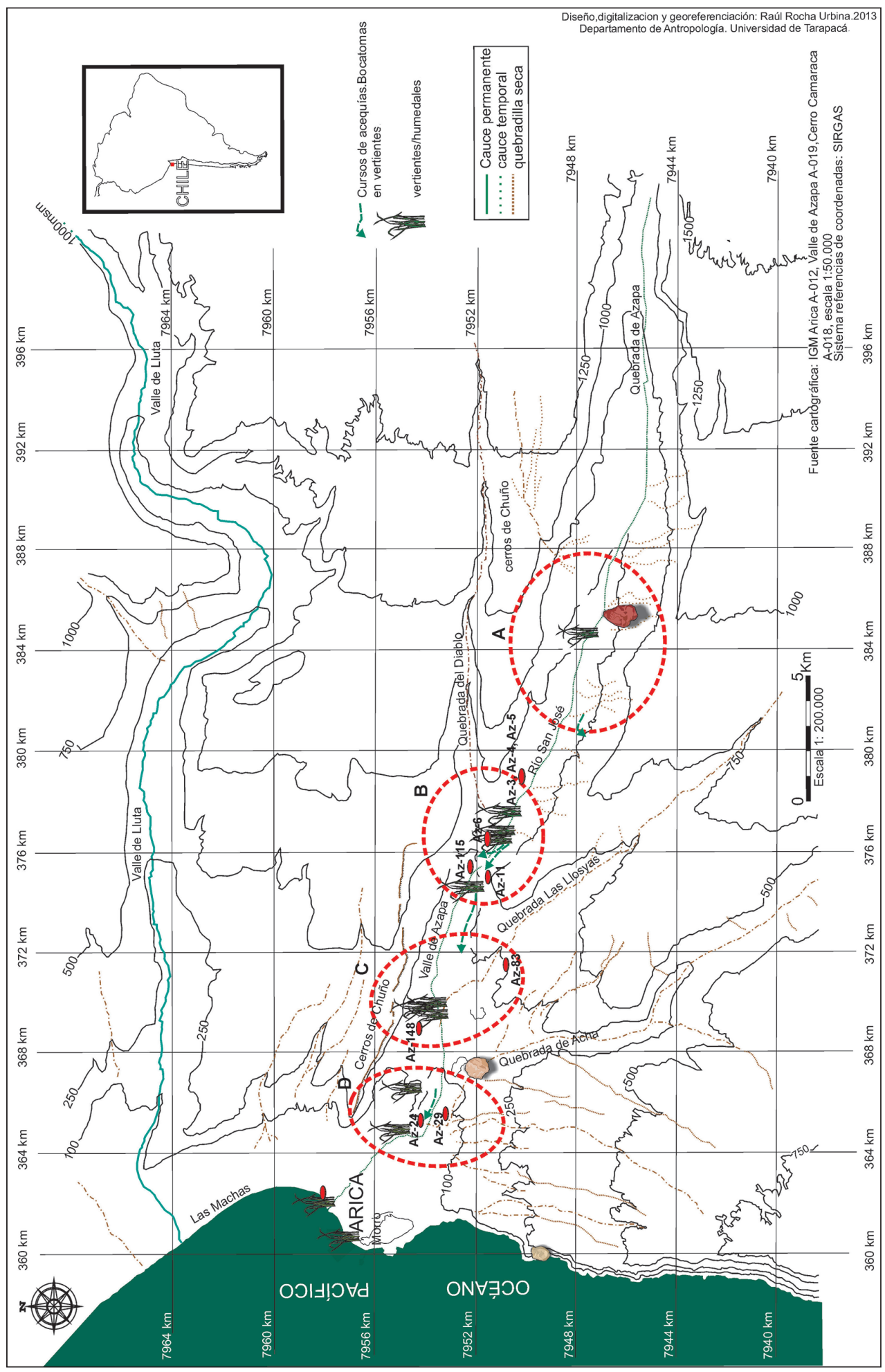

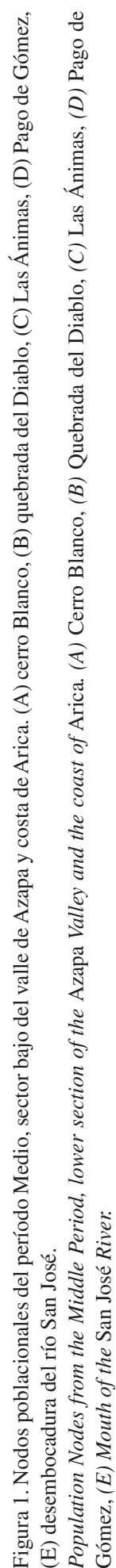



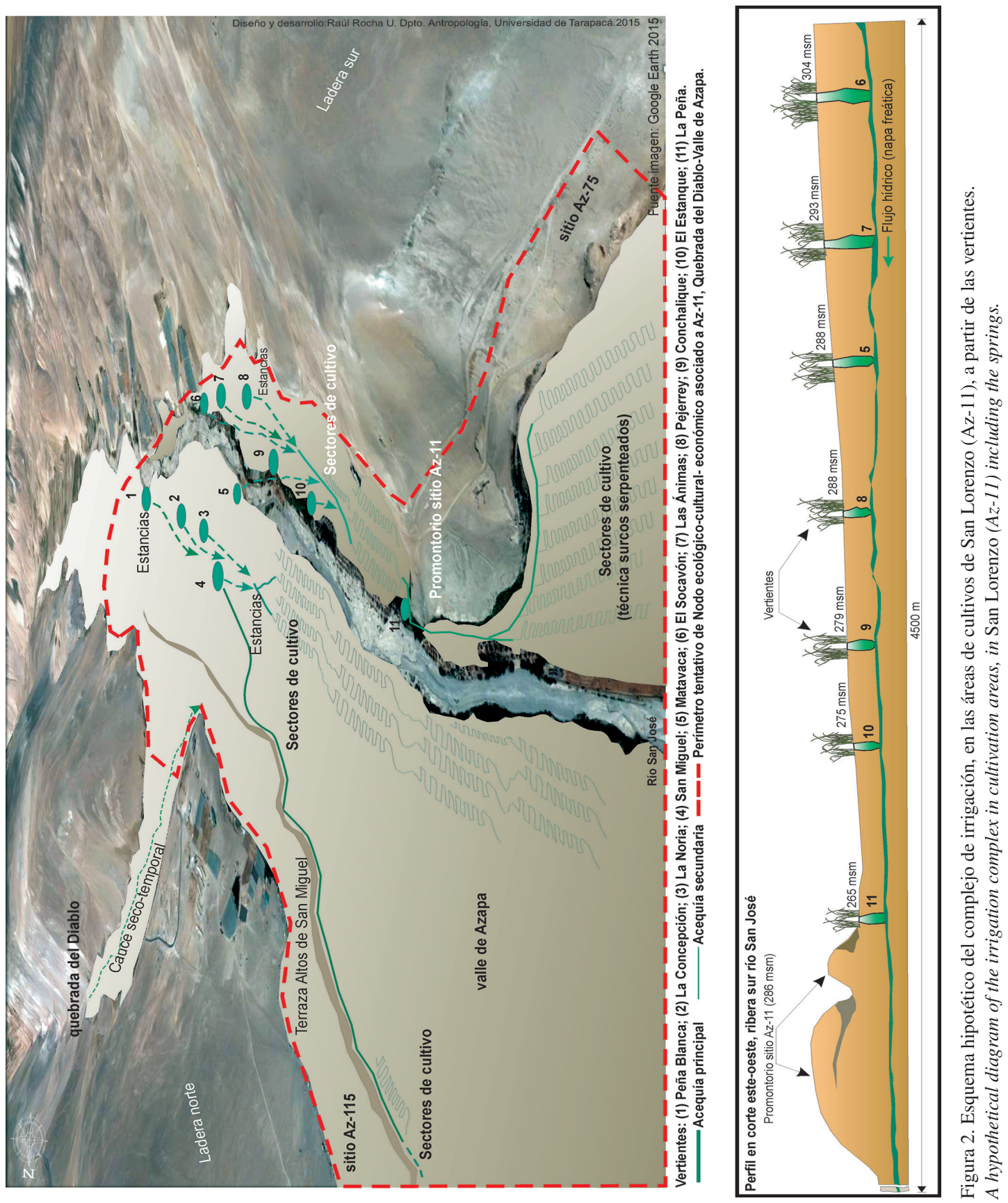
constató un segmento de acequia que presentaba un recorrido o lineamiento por la banda sur, en el sector de intersección del plano de terraza, teniendo como abrigo o protección los faldeos del cerro San Miguel. Junto con la explotación de agua, estos ecosistemas húmedos ofrecieron la extracción de especies vegetales (totora, caña, cola de zorro, etc.) utilizadas para la construcción de viviendas. El asentamiento Az-24, se beneficia de otro humedal, ubicado hacia el oeste en el sector de la Puntilla de Saucache. De la misma manera, la confluencia de quebrada de Acha con el valle de Azapa, determinó la existencia de afloramientos de agua y chilcales. En este sector se ubica el asentamiento habitacional Az-29, en la ribera sur del río San José; la captación de aguas para regar las plantaciones en este sector vincularía a este sitio además al ecosistema de Las Ánimas (Nodo C), cuyas aguas habrían sido transportadas por acequias.

En el espacio donde confluye el valle con la quebrada seca de Acha, se encuentran las últimas vertientes, y se tiene un amplio dominio visual de cota de playas, como playa Chinchorro, espacios determinantes en la configuración espacial entre costa y valle. Estos espacios están estrechamente vinculados a senderos y movimientos caravaneros, enlazados a su vez al trabajo de la tierra y la explotación de los recursos marinos.

El valle de Caplina. En este valle, los sitios registrados están asociados directamente a los sectores de Miculla, Para y Magollo (17²2'54S $70^{\circ} 36^{\prime} 22 \mathrm{O}$ ), cuyos ecosistemas corresponden a la parte media y baja del valle entre las cotas 1.200 a $200 \mathrm{msm}$, su fuente principal de agua era la del río Caplina y las aguas temporales del río Caramolle. Es probable que las aguas de ambas fuentes no desembocaran en el Pacífico, ya que sus cauces abastecían el riego de los terrenos que se ubican hasta la zona del Atajo o la Chimba a $169 \mathrm{msm}$, y los remanentes se perdían por filtración en el desierto de su gran delta. Desde Miculla hasta El Atajo son 49,18 km de distancia, con una geografía plana y continuada, donde el contacto y comunicación entre los asentamientos distribuidos a lo largo del valle pudo darse sin ninguna interferencia, facilitando sin duda cualquier actividad económica, social, religiosa y la defensa de sus áreas productivas, extractivas y el recurso agua. La distribución de distancias entre los sitios arqueológicos va desde $1,08 \mathrm{~km}$ (distancia mínima), hasta 12,3 km (máxima) (Figura 3).
No podemos asegurar si el dominio visual en este valle pudo contribuir a determinar espacios ceremoniales, por lo menos en el sector bajo del valle no se han registrado espacios o hitos de esta naturaleza. Sin embargo, en el extremo norte del sector medio del valle (Miculla) existe el cerro Wawapas que domina todo el espacio de la pampa de San Francisco, Miculla, Calientes y la unión del valle de Caplina con la quebrada de Palca. Es probable que el ари Wawapas tuviera el rol de espacio sacralizado para los asentamientos del período Medio (Miculla) de la zona de Pachía. En cuanto al manejo de espacios naturales para la extracción y explotación de recursos y materia prima, al parecer controlaron la cantera de sal (C19) y la cantera de piedra, ubicadas en las laderas del cerro Intiorko dominadas visualmente desde los sitios C10, C12 y C40. Con la piedra de cantería se prepararon morteros y manos para la molienda doméstica de granos y ají, encontrados en el sitio C66 (El Atajo), y tapas o cubiertas de las tumbas de los sitios C13 y C14. En el caso específico de C66 (El Atajo) se aprovecharon los cantos rodados de los cauces del Caramolle y el Caplina, para la preparación de morteros, batanes, manos de moler y soportes para la reparación de la arcilla. También se usó las canteras de sílice granulado ubicadas en la ladera del cerro Magollo al norte de C66, bolsones o bancos de arcilla y depósitos de fibra vegetal, que junto a las evidencias de hornos para la quema de cerámica nos sugiere una actividad alfarera (Figura 4 A, B, C, D y E).

En lo espacial hay una recurrencia entre los sitios domésticos, el cauce de río y las áreas productivas agrícolas asociadas a una red de acequias. Los sitios C10 (Copare 4), C12 (Magollo 2) y C40 (Magollo Sur 1) se encuentran en la caja del curso del río Caplina, sobre el lecho aluvial del cuaternario reciente, cuyos depósitos de greda se extienden sobre los estratos de arena y cantos rodados que fueron utilizados como campos de cultivo por los pobladores de dichos asentamientos. En el caso del sitio C66 (El Atajo), el asentamiento se fundó en torno a los excedentes generados por las avenidas de aguas temporales del río Caramolle, asociado a una red de canales y acequias para el riego de las chacras. C66, se caracteriza por el variado registro arqueológico que incluye basurales, talleres líticos, cerámica, textiles, hornos para la quema de cerámica, bancos de arcilla y vegetales, postes de viviendas, batanes, morteros, tendales 

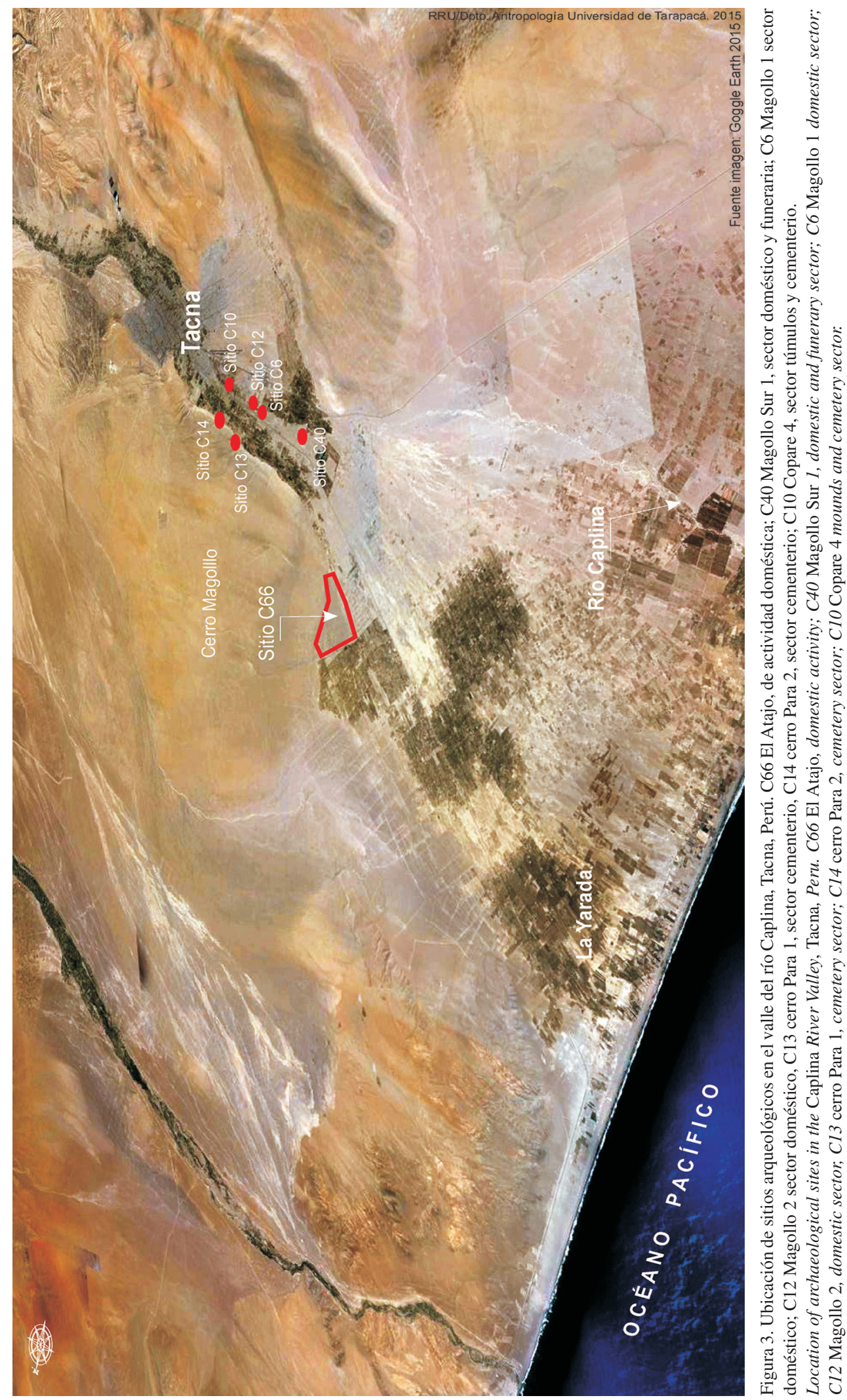


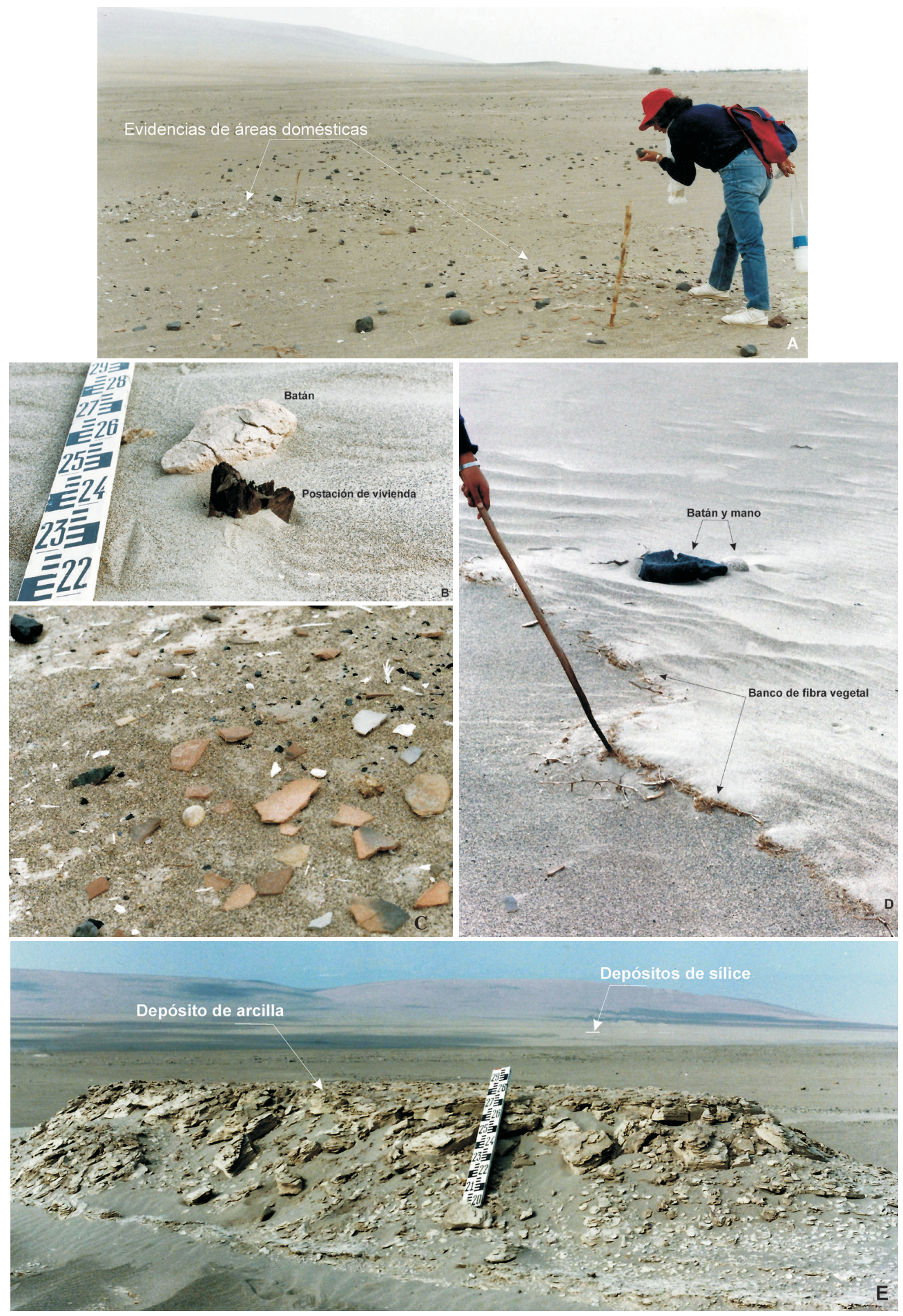

Figura 4. (A) Evidencias de recinto doméstico, sector NE. (B) Evidencias de postación de una vivienda. (C) Horno de cocción para greda-cerámica. (D) Herramientas y evidencias vegetales para uso de desgrasante. (E) Fuentes de materias primas. Sitio C66, El Atajo, valle del río Caplina, Tacna, Perú.

(A) Evidence of domestic settlements, NE sector. (B) Wooden pole, evidence of a dwelling. (C) Furnace for clayceramic. (D) Tools and vegetable fiber evidence used as degreaser. (E) Sources of raw materials. Site C66, El Atajo, Valley of the Caplina River, Tacna, Peru. 
de zapallo y restos alimenticios como ají, maíz, pescado, valvas marinas, cuy, etc. Todo ello nos habla de un sitio con mucha actividad doméstica y productiva que viene desde el Formativo Tardío hasta el período Medio. Observamos en esta recurrencia un patrón de asentamiento en donde las zonas domésticas se asocian directamente a las fuentes de agua, zonas productivas (áreas agrícolas) y materia prima para determinadas actividades de producción doméstica y funeraria. Los sectores funerarios se encuentran próximos a las áreas agrícolas, ubicados en las terrazas o laderas bajas del cerro Magollo (C13 y C14). En contexto, todo parece indicar que dicho patrón obedeció a una planificación previa del espacio, teniendo como ejes reguladores a las fuentes de agua y a la selección de los mejores suelos para la producción agrícola, y no muy distantes se ubicaron los cementerios. El caso de Miculla es diferente, se trata de un pequeño cementerio de tumbas tipo cista, con paramentos de cantos rodados, asociado a un conjunto de túmulos funerarios y de posible uso doméstico, ubicado sobre una terraza de la margen norte de la quebrada de Palca próximo a su unión con el Caplina. Al sur se extiende el complejo de petroglifos de Miculla, y el asentamiento doméstico más próximo es Tocuco (Trimborn 1975) ubicado a 2,6 km al norte. En este caso las fuentes de agua son el río Caplina (con un curso permanente) y el río Palca (intermitente) que alimentan áreas agrícolas de los sectores de Tocuco, Calientes, Miculla y Pachía. La distancia de C66 a la playa es de $15,4 \mathrm{~km}$, tramo que fácilmente se puede sortear en no más de una mañana incluidas algunas faenas de actividades económicas de pesca y mariscar machas y otras especies de moluscos y crustáceos.

\section{(2) Organización de los espacios interiores y exteriores de los asentamientos y áreas de actividad}

El valle de Azapa. En este valle ha sido posible registrar la organización de los espacios interiores y exteriores a partir de la información obtenida en los nodos poblacionales (sitios), sin embargo, la mayor cantidad de datos provienen del asentamiento Az-11. Las viviendas se construyeron sobre dos montículos que están separados por una pequeña depresión o cárcava. En el promontorio mayor se establecieron espacios entre los recintos destinados a vías de desplazamiento que comunicaban los recintos edificados a distintos niveles de altura. Las piedras fueron traídas de canteras próximas, donde no se hizo trabajo de cantería, sin embargo, los ejemplares de mejorar superficie fueron utilizados para mejorar esquinas de pircados tanto en las viviendas como en el muro perimetral. Se usó argamasa en la construcción de los cimientos de viviendas, su empleo mejora y fortifica las condiciones estructurales, constituyendo un elemento estético y un nuevo estilo constructivo.

En el interior de los recintos, como en Az-11, podemos visualizar las áreas de actividad tecnológicas y domésticas en pisos de ocupación. En R.14 el área doméstica se presenta focalizada en el vértice sureste del muro perimetral del terraplén, en él observamos la disposición de bloques líticos que encierran un pequeño espacio destinado a actividades de cocimiento. El piso está formado por un estrato compactado que incluye carbones, osamentas de animales (algunas de ellas quemadas), sedimentación mezclada con cenizas producto de la quema de maderos para cocimiento de productos $\mathrm{u}$ otras actividades ligadas a técnicas de cocción de cerámicas. En el piso interno se visualiza fragmentación de cerámicas y restos orgánicos vegetales, pero que conllevan a un tránsito humano relacionado con el traslado de líquidos y productos vegetales. En R.28, el piso interno presenta áreas de ignición asociados con fragmentación de cerámicas, osamentas de animales, a diferencia de R.14 donde el área de quema no está circunscrita a un perímetro artificial, fue hecha a campo abierto y no se preparó una hollada o depresión bajo el piso. En el fondo, no hay una hilera de piedras o construcción básica para actividades de cocimiento. En R.29, su vecino, se conservan dos áreas similares a la que existe en R.28, aunque con mayor densidad de osamentas de animales, fragmentos de cerámicas, además de la presencia de hilados y restos de cestería, se presentan como manchones de contornos irregulares, van desde el color negro hollín al ceniza sobre un estrato esencialmente rocoso. La presencia de restos de guano de cuy y camélidos infieren prolongaciones de áreas económicas llevadas a áreas residenciales, es probable que pequeños animales como perros y cuyes, muchos de ellos mascotas, hayan pernoctado en estos recintos habitacionales. La presencia de esteras de fibra vegetal bien conservadas existente en pisos de ocupación en el interior de los recintos, sugieren 
que su confección pudo hacerse en el interior de los mismos, otras en cambio de mayor tamaño, pudieron haberse confeccionados en el exterior.

La construcción de los recintos indica una actividad artesanal donde hubo un dominio de la cantería y de la topografía de los dos cerros que conforman el espolón rocoso donde se asentó el poblado, de tal manera que fue necesario evaluar y diagnosticar la superficie de los montículos, seleccionar las áreas a construir, conocer las fuentes de suministro de materias primas (material pedregoso), organizar su transporte utilizando canastos y capachos, etc. Esta cadena operativa requirió de una organización y planificación jerárquica y compromiso de la población con el trabajo comunitario.

En el Nodo C, la planificación residencial de Az-83, mediante la interpretación fotográfica, fue orientada en su eje mayor de noroeste a sureste, sobre los $300 \mathrm{~m}$ hacia el interior de la quebrada y avecindada con el curso seco de la quebrada de las Lloyllas, esta particularidad indica trazados de acequias para llevar agua a lugares desérticos que originaron un desarrollo agrícola y un sustento para la población que ocupó ese espacio. En el Nodo $\mathrm{D}$, en el asentamiento Az-29 registramos una clara delimitación del espacio interior de los recintos excavados con muros de caña. En algunos de estos recintos encontramos restos de implementos y materia prima con la que confeccionaron cerámica y textiles, lo que sugiere espacios para elaborar tecnologías.

El valle de Caplina. En este valle, a diferencia de Azapa, las excavaciones en sitios domésticos del período Medio son menores, lo cual no permiten definir con mayor claridad la organización de los espacios interiores y exteriores del asentamiento. Sin embargo, es el sitio El Atajo (C66) el que presenta algunas evidencias en torno a su modelo de asentamiento y áreas de actividad tanto externas como internas. A diferencia de El Atajo, otros asentamientos, se instalaron en la caja del valle, y corresponden a sitios con actividad doméstica construidos sobre terraplenes y vinculados a una importante red de canales y espacios agrícolas, utilizando los recursos hídricos del Caplina y las entradas temporales del río Caramolle. En el mismo valle, cercano al curso de agua, se obtuvieron las materias primas como cantos rodados, troncos, cañas y barro para la construcción de sus viviendas. La topografía del valle facilitó el riego por gravedad, la construcción de espacios agrícolas y la intercomunicación entre el valle y la costa. El acceso a la precordillera y al altiplano puede haber sido posible a través del corredor natural de la quebrada de Palca y el Huaylillas.

\section{(3) Vinculación de los asentamientos con senderos, figuras rupestres e hitos geográficos demarcatorios}

El valle de Azapa. En Azapa, el registro sobre senderos, figuras rupestres e hitos geográficos demarcatorios y su vinculación con asentamientos enclavados en distintos nodos, se presentan en ambas laderas del valle. En la ladera norte hemos registrado trazos de senderos desde Az-3, Az-4 y Az-5 hasta el borde costero. Por su parte en la ladera sur observamos tramos cortos de senderos que están vinculados a afloramientos naturales de calcedonia y cuarzo. Estos puntos de conexión son directos, no hay registros de apachetas u otros componentes que marquen zonas de paradas para realizar ceremonias. Estos senderos no presentan una preparación de delimitaciones laterales que pudieran estar conformados por lineamientos de piedras. Respecto a las canteras, estas se ubican distantes con respecto al plano de valles, más bien ocupan cotas de ladera y cima de cerro. Estos puntos se han detectado en la terraza del Chuval, Puntilla de Cabuza, serranías del sector las Riberas y las pampas altas del sector de cerro Chuño (Muñoz 2004b).

Respecto a los petroglifos, observamos que algunos conjuntos están directamente vinculados con asentamientos habitacionales y funerarios, dentro de un espacio sectorizado, como son los casos de Az-3, Az-4, Az-5, Az-11, Az-148. En Az-3, Az-4 y Az-5, en ellos se manifiesta una tipología de tallados profundos reconocidas como modelo de piedras tacitas. En cambio en Az-11, observamos figuras relacionadas con el entorno paisajístico como soles, llamas, figuras antropomorfas, aves, etc., mostrando una mayor diversidad de figuras. Por otro lado, en Az-148, fue hallado un bloque con una representación de la figura de un pez (tuna), sugiriendo una vinculación de los seres humanos con su medio, en este caso la costa y el sector bajo del valle. 
Desde el punto de vista de la visibilidad, es posible observar una relación espacial entre asentamientos y entorno, es así que se aprecia la existencia de caminos trazados que conectan el valle con la desembocadura del río San José y las distintas zonas del litoral. Los asentamientos de Az-24 y Az-29 vinculados con el Nodo D se hayan relacionados a sectores como Saucache, cerro Sombrero y los Altos de Acha, proyectándose hacia el valle de Chaca y Codpa. Por el oriente registramos senderos que se dirigen hacia la quebrada de Livilcar y los valles de Belén y Chapiquiña. La información espacial que arroja la distribución de nodos indica que cada uno de ellos presenta sus propias redes viales que alcanzan distintas direcciones en el valle y más allá de este.

Respecto a la visibilidad que ofrecen los hitos geográficos, la mayor representación es la cadena de cerros que conforman pequeñas serranías y lomajes, tanto en el valle de Azapa como en la costa. En este contexto, pensamos que el hito más antiguo enclavado en la costa de Arica pudo haber sido lo que hoy es el Morro de Arica, sin embargo durante el desarrollo agrícola y en la medida que las poblaciones fueron ampliando las zonas de cultivo en el valle, se pudieron incorporar nuevos referentes geográficos en la memoria de estas poblaciones como cerro Chuño, cerro Sombrero, el peñón de San Lorenzo, etc.

El valle de Caplina. En el Caplina, la red caminera antigua está registrada fundamentalmente para los períodos Intermedio Tardío e Inca (Gordillo 1993, 2000), y en gran medida relacionada a los sitios de petroglifos del valle. La red vial directa que conectaba a los asentamientos del período Medio en el Caplina no se conservan, sin embargo, es probable que los senderos fueron trazados en el fondo del valle, bordeando las riberas de los cauces, de tal manera que los sitios C12, C6, C40 y C66 quedaran totalmente conectados, articulando también a los sitios funerarios de $\mathrm{C} 10$ (ubicado en el fondo del valle), C13 y C14 (ubicados en la ladera del cerro Para). Desde ahí, la red distribuida era directa hacia los espacios productivos y de obtención de materias primas como arcilla, piedra de cantería y cuarzo, sin parajes intermedios como apachetas y paraderos de descanso en vista que las distancias son cortas y de fácil visibilidad y desplazamiento. La conexión con la cuenca desde Palca, pasando por Miculla y Pachía está marcada por la presencia de un camino registrado y mencionado por varios viajeros y arqueólogos, entre ellos: Andrews en 1825; Squier en 1863, Paz Soldán en 1860; Raimondi en 1864 (Cavagnaro 1986), cuya conectividad se proyectaba hasta la zona precordillerana y la cuenca occidental del lago Titicaca, a través de un sendero delimitado con muros laterales, muros de contención, puentes y otros rasgos característicos de los caminos andinos que unen las alturas con la costa (Gordillo 1993, 1996). Desde Miculla, valle abajo, el tramo caminero es bien marcado conectando todo el valle con proyección hacia el valle de Azapa y ramificaciones laterales rumbo al valle de Sama, Locumba, Tarata y Lluta (Gordillo 1993).

En el caso de petroglifos asociados directamente a los sitios del período Medio en los sectores de Para y Magollo, no tenemos mayor referencia que el sitio C3, ubicado a la altura del actual aeropuerto de Tacna, al este de los sitios C10, C13 y C14, y al noreste de los sitios C12, C6, C40 y C66. Corresponde a un petroglifo con una figura humana con tocado cefálico, asociada a motivos geométricos. A partir del sector de Pocollay, se ha registrado un promedio de diez sitos con petroglifos, siendo Miculla el más emblemático, que están conectados a la ruta caminera Huaylillas-PalcaMiculla-Pachía-Calana-Pocollay. Al noroeste de los petroglifos de Miculla se ubica el sitio Túmulos de Miculla, asociado a un pequeño cementerio de cistas de filiación Tiwanaku, conectado directamente al tramo caminero de Miculla-Palca.

Con relación a la red vial vinculante con el valle Caplina, está el "Camino de los Llanos" que conecta los sectores medios de los valles Sama y Locumba, y el "Camino del Litoral" o de la Costa, que domina toda la franja continental del mar, siendo el tramo más visible el registrado en "Morro Sama" y "Punta Picata". Consideramos que esta red, sumada a los pequeños tramos de penetración, facilitó enormemente la intercomunicación entre los sitios del período Medio del Caplina, Sama, Locumba, Azapa, y sus nexos con el altiplano puneño.

Los referentes geográficos más relevantes en los sectores de Para y Magollo son los cerros Arunta al sureste y el Intiorko al noroeste, que conforman elevaciones de mediana altura ( 250 a 400 $\mathrm{msm}$ ) y delimitan la parte media del valle. Hacia el este sobresalen las montañas de la quebrada de Palca Huaylillas y los nevados Barroso, Tacora y Chupiquiña que son visibles desde Para y Magollo. 


\section{(4) Extensión y características del espacio donde se asentaron las poblaciones}

Valle de Azapa. El sitio San Lorenzo (Az-11) se constituye como el asentamiento de mayor envergadura, con un área de 2,7 ha aproximadamente, vinculado a las poblaciones del período Medio. En la cima de este abrupto montículo observamos un uso planificado del espacio con la técnica constructiva aterrazada, lo que les permitió tener una mejor distribución de la población versus las actividades tecnológicas, económicas y rituales que se llevaron a cabo. A pesar de su espacio reducido a primera vista, este promontorio ofrece una serie de alternativas favorables para el asentamiento humano: la readecuación de determinados espacios para la construcción de grandes recintos cuya visibilidad les permitió un posicionamiento estratégico (Figura 5 A, B y C). Su cercanía a las vertientes La Media Luna y el Gallito, y sus respectivos humedales, facilitó la obtención de materias primas (cañas, totora, pajonales, yaro, molle, pimiento, pacae, chilca, algodón) para el desarrollo de los sistemas constructivos, a su vez las características propias de los cerros de San Lorenzo permitió acceder de manera directa a recursos áridos (piedras) con los que fueron construidas terrazas habitacionales y tumbas, entre otros tipos de construcciones.

Desde el punto de vista visual observamos que el matiz cromático de la superficie del promontorio, gris blanquecino verdoso, se diferencia de la tonalidad que predomina en la ladera sur, que corresponde a un matiz rosáceo blanquecino, lo cual a cierta distancia permite establecer diferenciaciones cromáticas de tonalidad, constituyéndose en un elemento importante que contrasta con el paisaje y por lo tanto su ubicación.

Otros asentamientos que nos aproximan a un cálculo de área corresponden a: Az-3, Az-4 y Az-5, que en su conjunto abarcan 1,7 ha, ubicándose a 340 $\mathrm{msm}$. En este sector se conjugan simultáneamente el área habitacional, funeraria, ritual y económica. Por las condiciones naturales que ofrece el promontorio de cerro Moreno (protección del viento), fue un albergue natural adecuado para un asentamiento humano, proveyéndolos además de material lítico ignimbrítico, complementado con bloques para la talla de petroglifos. Considerando las evidencias que se conservan en la actualidad, podemos inferir que los campamentos se situaron ocupando cotas de base del valle asociadas con la ladera norte y cobijadas por el promontorio de cerro Moreno.

Por su parte, Az-6 y Az-115 se encuentran en cotas de base de la ladera norte, sobre una terraza fluvial. El primero se ubica hacia el vértice este de la terraza, cercano a la confluencia de la quebrada del Diablo con el valle de Azapa, mientras que Az-115 se ubica hacia el vértice oeste de la terraza Altos de San Miguel, ambos se benefician de un ecosistema de vertientes y humedal. El cementerio Az-6 tiene una dimensión de 1 ha, su altura bordea los $300 \mathrm{msm}$. La superficie del sitio presenta un gran pedregal de bloques de gran volumen que podría constituir material de arrastre de aluvión proveniente de la quebrada del Diablo. El asentamiento Az-115 es una superficie plana, levemente inclinada en dirección a la caja del valle, en sentido norte sur, ocupa el borde sur del valle. Presenta un área de 0,7 ha. Si bien es un sitio funerario, el asentamiento humano debió haber estado en lugares protegidos en la ladera del cerro, donde hemos encontrado pisos de ocupación con restos de actividades doméstica (desecho y cocina) y pequeñas depresiones asociadas a restos de totora, lo que sugeriría un campamento temporal.

El asentamiento Az-83 se ubica a $245 \mathrm{msm}$ sobre el plano de la terraza Alto Ramírez, orientado hacia el interior de la quebrada las Lloyllas y en estrecha relación con el cauce seco de esta quebrada. Corresponden a pequeñas depresiones de forma circular y semirrectangular, las dimensiones de esta aldea según interpretación aerofotográfica descrita por Rivera (1983) señalan que el eje mayor promedia $70 \mathrm{~m}$ orientado de este a oeste, mientras que de norte a sur promedia $35 \mathrm{~m}$. El ambiente donde se construyó esta aldea es desértico con ausencia de vegetación nativa a excepción de la vegetación que crece en el cauce de la quebrada las Lloyllas cuando escurre agua.

En el cerro San Miguel se halla el asentamiento Az-24. Este cerro en el contexto espacial se presenta como un cerro "isla" que ha albergado a varias ocupaciones humanas en época prehispánica hasta en la actualidad. La presencia de este asentamiento al parecer estuvo relacionado con la existencia de vertientes, ubicadas en el margen noreste y noroeste del cerro mismo, permitió que se establecieran redes de acequia para irrigar melgas de cultivos, las que fueron preparadas en la misma terraza que alberga el asentamiento orientándose hacia el oeste. El área residencial estuvo ubicada en el vértice noroeste del cerro San Miguel, orientando su dominio visual 


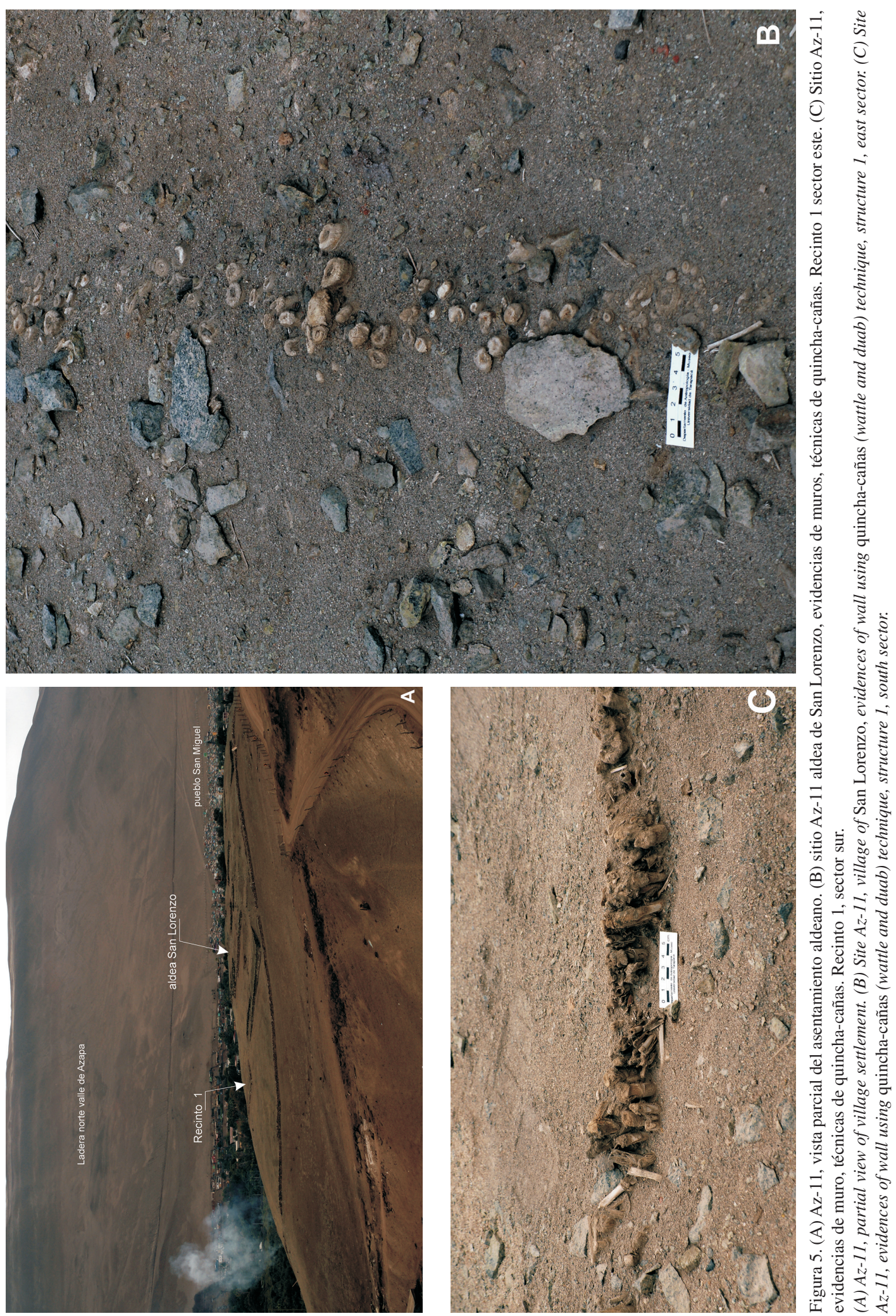


hacia el valle. La presencia de restos de basuras, fogones y fragmentación ceramológica refuerza este planteamiento.

El asentamiento Az-29 corresponde a un emplazamiento habitacional, el que presentaba un amplio domino visual, conectado con redes viales que se dirigían hacia la costa sur de Arica (playa Quiani) y las guaneras de las cuevas de Anzota. Las excavaciones evidenciaron muros de caña de viviendas de forma rectangular, en hiladas simple, doble o mixta (Figura 6 A y B). En su espacio interior, se hallaron restos de muros de caña que dividían el espacio cuya función al parecer, fue de vivienda y actividades domésticas; además, en uno de estos recintos se hallaron pequeños fogones-hornos para cocer cerámica, el hallazgo de instrumentos para hilar y tejer como vichuña, torteros y lana sugiere la idea de una actividad textil realizada en el interior de estos recintos.

El valle de Caplina. El sitio C10, se ubica en el fondo del valle en el sector de Para, con una extensión de 6,6 ha. Se encuentra asociado al cauce antiguo del río Caramolle. Presenta cuatro sectores diferenciados: Sector A, es un conjunto de formaciones tumulares elípticas, las que se hallan dispuestas de norte a sur. El sector B, es un área agrícola definida por surcos lineales conectados a canales principales y de drenaje. El canal principal se desplaza desde los sitios C4 y C5 y los canales secundarios se ubican horizontalmente con relación a la posición perpendicular de los surcos. Esta área agrícola está unida por un pequeño canal secundario. El sector C, está definido por un promedio de 200 depresiones circulares y elípticas de poca profundidad, aglutinadas y de diámetro variado ( $2 \mathrm{~m}$ promedio). El sector $\mathrm{D}$, son un conjunto de depresiones de similares características a las del sector C, ubicado a unos 80 metros al sur del sector C.

$\mathrm{El}$ sitio $\mathrm{C} 12$, corresponde a una zona doméstica con características muy peculiares, delimitando un área de 11,2 ha. El sitio se ubica en el fondo del valle del sector agrícola de Magollo, a $322 \mathrm{msm}$. A pesar de su destrucción, se observa un sector doméstico definido por alineamientos de cantos rodados y depresiones de planta rectangular que probablemente sirvieron de base para el levantamiento de recintos de quincha. El sitio C40, de posible función doméstica, tiene una extensión de 20,3 ha y registra cuatro concentraciones de cerámica, herramientas como azadones y chancadores, desechos líticos y algunas estructuras de concentraciones o amontonamientos de cantos rodados muy similares a las encontradas en el sitio C8.

El sitio C66 (El Atajo) se ubica sobre la cuenca del drenaje terminal del río Caramolle, al oeste de la ciudad de Tacna, ubicado en una gran planicie de depósito aluvial que se extiende entre las actuales irrigaciones de Magollo y la Yarada, a una altitud de $196 \mathrm{msm}$ y a 19,5 km distante de la línea de playa del Pacífico Sur. Los trabajos de prospección realizados en el sitio han puesto al descubierto varios conjuntos de restos de viviendas dispersas cuyos postes y utillaje doméstico (cerámica, líticos, batanes, instrumentos de tejer, agujas, cuentas de turquesa, peines, otros), aún se pueden observar sobre la superficie en directa asociación a restos de alimentos marinos como valvas de choro zapato, conchas de machas, espinas de pescado y restos de alimentos terrestres como huesos de camélidos y cuy, maíz y tendales de cucurbitáceas. Por otro lado, se han identificado restos de fogones (cocinas) delimitados con cantos rodados. En el sector oeste del sitio existen numerosos depósitos de arcilla con indicios de haber sido explotados. Estos depósitos, aparecen asociados a posibles "bancos" de fibra vegetal seleccionada, batanes y manos, restos de postes de viviendas, posibles canales, cerámica, líticos, restos de carbón y hornos para la cocción de cerámica. En los hornos, hay restos de carbón, ceniza y cerámica semicocida. Al norte del sitio ubicamos una cantera de sílice granulado cuyo material se empleó como desgrasante de la cerámica. Los hornos se presentan como grandes lentes o pequeños montículos circulares u ovalados de arcilla quemada y restos de ceniza y carbón. Están ubicados a poca distancia de las canteras de arcilla y de las áreas domésticas, en sectores favorecidos por los vientos. La cerámica es mayoritariamente del período Formativo Tardío y en menor escala se han registrado fragmentos de cerámica del período Medio de filiación Tiwanaku.

\section{Conclusiones}

Retomando la pregunta de investigación, sobre ¿cómo se desarrollaron y complejizaron los asentamientos habitacionales en los valles de Azapa y Caplina? Desde un punto de vista comparativo, podemos señalar que los grupos familiares, fueron los entes conectores en la formación de las sociedades semicomplejas que actuaron bajo 

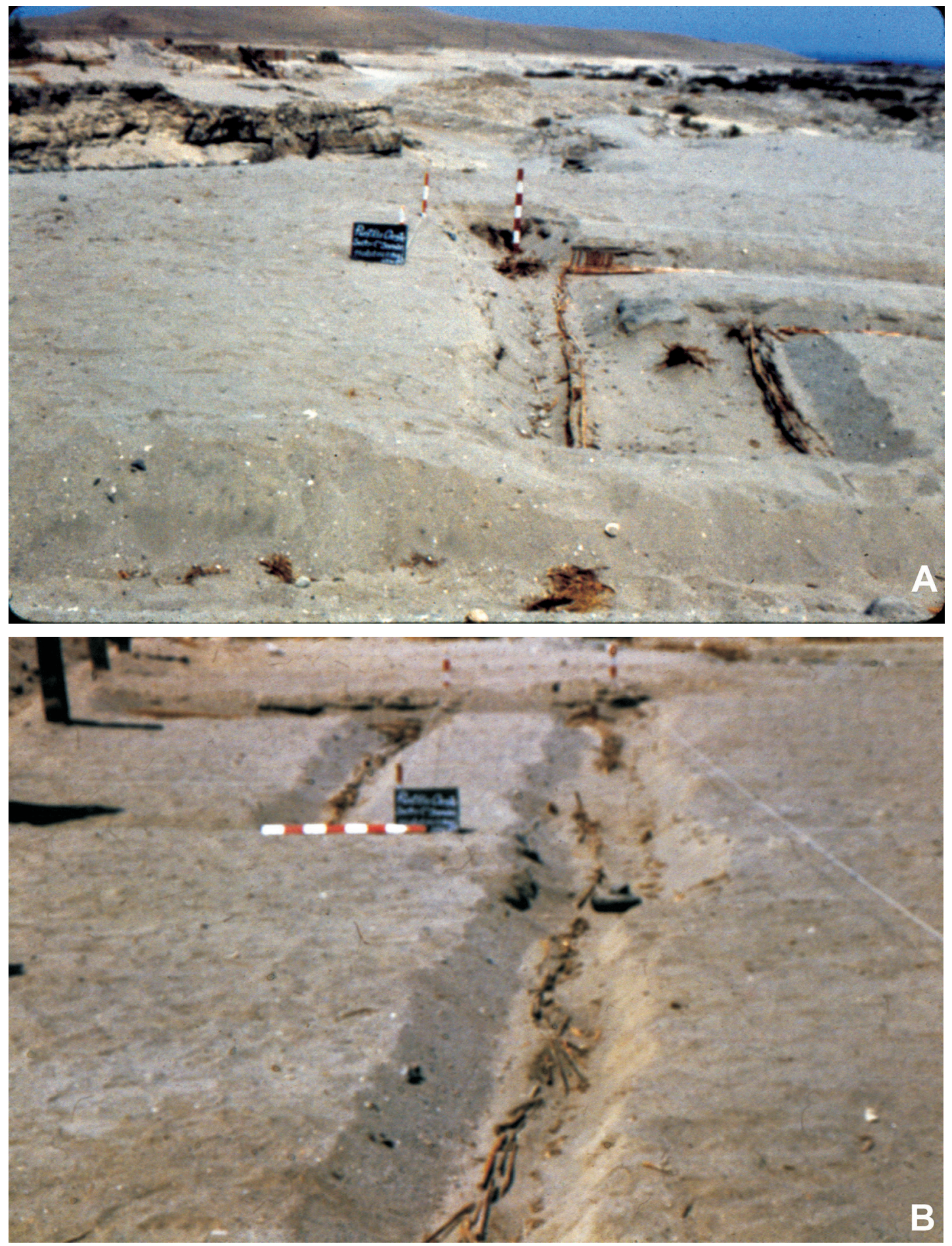

Figura 6. (A) Sitio Az-29, cimientos de viviendas de cañas, sector sur, Recinto 1. (B) Sitio Az-29. Cimientos de vivienda de cañas, Recinto 1 , muro sur.

(A) Az-29 site, foundations of reed housing, south sector, structure 1. (E) Az-29 site, foundations of reed housing, structure 1, south wall. 
un común denominador: poseer espacios donde vivir y desarrollar sistemas de subsistencia; esto sumado a la detección de recursos naturales que pudieron haber sustentado el desarrollo de los campamentos y aldeas. En ambos valles se observa el desarrollo de una planificación del entorno, así por ejemplo, ocuparon terrazas altas para evitar ambientes malsanos propios de la alta humedad de los sectores bajos contiguos a los cursos de agua, sin embargo, al agua se le asigna la vital importancia en el contexto de la subsistencia humana, animal y vegetal.

Las primeras ocupaciones del desarrollo agrícola del valle de Azapa, están vinculadas a la explotación de las vertientes y suelos agrícolas, por lo tanto lo que observamos son pequeños asentamientos, a nivel de campamentos, cuyas técnicas de construcción fueron muy básicas. Esto pudo deberse a que eran poblaciones que no mantenían una residencia permanente en el valle, sino que su área nuclear pudo haber estado en la costa. Sin embargo, a pesar de esta permanencia temporal en el valle, su mayor marcador de territorialidad fue la construcción de cementerios, especialmente los túmulos. Por lo tanto, los recintos habitaciones no tuvieron una importancia destacable, sino que se constituían como espacios para abrigarse y pernoctar. Todo indica que el hábitat mayor fue el sector que estuvo constituido por la vertiente, los cementerios y los cerros protectores. Esto también se observa en el Caplina, donde los cementerios por su número y tumbas que concentran, adquieren real importancia al parecer más que los recintos habitacionales. Esta forma de habitar se habría prologando durante el período Medio, con excepciones muy notables como el sitio San Lorenzo en Azapa y El Atajo en Caplina, que se habrían constituido como las primeras aldeas propiamente tales en ambos valles.

Sin embargo, en Azapa a partir del 500 d.C. el poblamiento aldeano habría requerido de un enclave articulador cuando la economía agraria fue sustentable y perdurable, este asentamiento debió ser el eje donde coincidieron gente de la costa y del valle, de tal manera que, de un poblamiento disperso que giró en torno a los nodos poblacionales, es posible que con la integración de su población haya emergido el poblado de San Lorenzo como una unidad poblacional que unió las pequeñas aldeas distribuidas a lo largo del valle, que se conectaban con los recursos de agua y que fueron parte de los distintos nodos poblacionales en el valle. En esta aldea de "San Lorenzo", es posible que se hayan articulado ideas y expresiones culturales propias de enclaves periféricos de los valles costeros.

En relación con el Caplina, es el sitio El Atajo, el cual por su extensión, cercanía a la costa, evidencias en torno a áreas de actividad; el que se constituyó como un eje articulador de relaciones sociales y económicas, similar a San Lorenzo. No obstante, es necesario reconocer que San Lorenzo, por su ubicación estratégica, en altura, con un dominio visual de la costa hasta el interior del valle, con un sistema constructivo técnicamente complejo, como fue edificar recintos en la cima de montículos, sobre distintos niveles de aterrazamiento, representa un modelo arquitectónico único y distinto a El Atajo cuya construcción fue en plano.

Por las características arquitectónicas que ofrece El Atajo constituiría el asentamiento humano más visible, durante el período Medio en el valle de Caplina, en él probablemente interactuaron agricultores locales con colonos Tiwanaku provenientes del valle de Moquegua. Por otro lado, la presencia de túmulos funerarios muy similares a los de Azapa, es otro hito que aún no ha sido discutido y que podría ayudar a entender la dinámica del desarrollo del período Medio en el Caplina. La gran dispersión de estos montículos en dicho valle estaría delatando un sorprendente poblamiento humano producto de un antiguo desarrollo cultural costero, que al igual como señala Núñez (1989:91-92) se remontaría al séptimo milenio antes del presente.

Los asentamientos del período Medio en el Caplina tomaron control de los mejores espacios productivos en términos de calidad de tierra en Para y Magollo para el cultivo de maíz, calabazas y ají, y de aquellos sitios de explotación de materia prima como canteras y arcillas. Probablemente, hicieron lo mismo con la infraestructura hidráulica implementada por los aldeanos de El Atajo y las poblaciones de los túmulos. En las cabeceras del valle probablemente se posesionaron en las zonas de Miculla, Calientes y Tocuco para ejercer el control del agua. Una vez puesto en marcha el modelo, debió inaugurarse un tráfico fluido de bienes y servicios con la costa, los valles adyacentes y con el altiplano. En este contexto, la cercanía de los asentamientos Omo y Chen Chen, en el valle de Moquegua, considerados como los dos sitios Tiwanaku más importantes de la periferia occidental fuera del centro epónimo (Goldstein 1998:45-58), debieron ser un referente 
importante para los asentamientos del período Medio en el Caplina.

El análisis de la ocupación del espacio y uso de los recursos naturales, en la conformación de aldeas y campamentos durante el período Medio, presenta similitudes en ambos valles, teniendo como ejes centrales la participación de poblaciones vallunas costeras en la planificación y organización de las poblaciones que dieron origen y desarrollo al proceso de agriculturización. Sin embargo, en el Caplina no hay un asentamiento a la fecha, que sintetice la historia de un valle a partir de la integración comunitaria como es posible determinarlo en la aldea de San Lorenzo. A diferencia de Azapa, en el Caplina, a través del sitio El Atajo, se observa un poblamiento aldeano de tradición local vinculado con los asentamientos tiwanacotas venidos principalmente del valle de Moquegua.

\section{Comentarios Finales}

En el valle de Azapa, una vez resuelto el problema hídrico, las poblaciones debieron haber evaluado los recursos naturales disponibles, especialmente los relacionados con las áreas cenagosas y/o humedales, esto derivó en la adquisición de conocimiento y un posterior desarrollo paulatino de carácter tecnológico, orientado al aprovechamiento de esos recursos naturales, como los usados en la arquitectura doméstica, ceremonial, económica (corrales) y ritual (funeraria) (Tabla 1).

Los logros alcanzados en la producción y diversificación agrícola que observamos en el período Medio, habría motivado el desplazamiento definitivo de las poblaciones al valle, dejando la franja costera para las actividades extractivas. La alta calidad de las aguas y suelo del valle de Azapa, a diferencia de otros valles, permitió el desarrollo de una producción agrícola mayor, la que desde muy temprano se habría transformado en un polo económico atractivo, esto habría conllevado al desarrollo de una red de intercambio con otras poblaciones, las que habrían aportado con objetos, iconos, productos, conocimientos artesanales y tecnológicos, materias primas, plantas, animales etc., propias de otros valles y regiones de los Andes. Este fenómeno habría generado cambios en la estructura económica y social, conduciendo a los líderes de cada uno de los nodos poblacionales a buscar fórmulas para una mejor administración de una población que iba en aumento demográfico.
De esta manera, se requirió una organización que mantuviera la homogeneidad de las políticas propias del valle, surgiendo la propuesta de construir un asentamiento más complejo desde el punto de vista arquitectónico el que además, cumpliera la función de un referente visual que integrara y gravitara en cada uno de los individuos que ocupaban el espacio bajo del valle. Su ubicación estratégica, cercana a la confluencia de quebradas y valle donde se halla el ecosistema verde de mayor extensión, habría sido la clave para que se definiera el asentamiento de San Lorenzo (Az-11) como el poblado eje que habría articulado a los agricultores del período Medio, constituyéndose en un centro administrativo a través del tiempo.

En el caso del Caplina, el recurso hídrico y su manejo fueron los referentes más importantes para el desarrollo de los asentamientos aldeanos y su mantenimiento sostenible en el tiempo. El manejo de este recurso impulsó el desarrollo de una agricultura en ascenso y la construcción de una red de canales y acequias, la que probablemente fue impulsada desde los pobladores de El Atajo y ampliada durante el período Medio. La observación del espacio y el diseño de mecanismos para el uso y explotación de sus recursos naturales fue el paso siguiente que asumieron sus pobladores, lo que generó un patrón de asentamiento acorde a los recursos del medio y a las relaciones dentro y fuera de su territorio. Si bien es cierto, al igual que en Azapa, el período Medio en el Caplina no se caracteriza precisamente por la existencia de una compleja arquitectura monumental ni por una densidad de asentamientos diversos y complejos, sino al contrario, se implementó un modelo de asentamiento definido por pequeñas aldeas con estructuras habitaciones simples, construidas con recursos de los ecosistemas de la zona (madera, cañas, barro, cantos rodados). Estas aldeas se ubicaron en la ribera de los cauces del Caplina y el Caramolle, asociadas a los espacios productivos agrícolas y probablemente a las materias primas como canteras de arcilla y líticos (Tabla 2). Estas aldeas se habrían constituidos en el principal centro de operaciones desde donde se planificaban las actividades cotidianas familiares, las productivas y aquellas relacionadas a la cohesión social y las relaciones con otros grupos del valle y fuera de él, como la costa.

El Caplina durante el período Medio se constituyó en un centro y núcleo impulsor de estos 
mecanismos de relaciones con la existencia de aldeas dispersas que en algún momento pudieron haber construido una estructura de liderazgos, al igual que en Azapa, que se encargaron de manejar la creciente población, los excedentes de producción agrícola y demás bienes, y sobre todo, mantener la homogeneidad de las decisiones políticas en el valle y de la integración social de las aldeas dispersas en él. Para el caso de Azapa, el sitio de San Lorenzo (Az-11) pudo alzarse como el referente integrador y articulador de las políticas del valle; sin embargo, en el Caplina no se ha registrado un sitio administrativo con similares características.
Agradecimientos: Este artículo es producto de la investigación desarrollada en el marco del proyecto Fondecyt 1130249. Se reconoce el apoyo del Convenio de Desempeño Universidad de Tarapacá-Mineduc. Se agradece la colaboración del Sr. José Raúl Rocha encargado de la Oficina de Catalogación del Departamento de Antropología de la Universidad de Tarapacá con quien prospectamos y discutimos la problemática del valle de Azapa, y por elaboración de las figuras y tablas que ilustran el presente texto. Igualmente se agradece a los evaluadores anónimos por el tiempo dedicado a la lectura y comentarios a este trabajo.

\section{Referencias Citadas}

Adán, L. y S. Urbina 2011. Arquitectura quebradeña del complejo Pica-tarapacá: Modos de hacer, opciones de diseño, rasgos significativos y decisiones funcionales. Actas del XVII Congreso Nacional de Arqueología Chilena, 2006. Tomo 2, pp. 865-876, Valdivia.

Albarracin-Jordan, J. y J.E. Mathews 1990. Asentamientos Prehispánicos del Valle de Tiwanaku, Vol. I. Producciones Cima, La Paz.

Aldenderfer, M. 1993. Domestic space, mobility, and ecological complementarity: The view from Asana. En Domestic Architecture, Ethnicity, and Complementarity in the South-Central Andes, editado por M. Aldenderfer. University of Iowa Pres, Iowa City.

Cavagnaro, L. 1986. Materiales para la Historia de Tacna (Cultura Autóctona), Tomo I. Editado por la Cooperativa San Pedro de Tacna, Tacna.

Chacama, J. 2004. El Horizonte Medio en los valles occidentales del norte de Chile (ca. 500 - 1.200 d.C.). Chungara Revista de Antropología Chilena Tomo I, pp. 227-233.

Conrad, G. 1993. Domestic architectuire of the Estuquiña Phase: Estuquiña and San Antonio. En Domestic Architecture, Ethnicity, and Complementarity in the South-Central Andes, editado por M. Aldenderfer, pp. 55-65. University of Iowa Press, Iowa City.

Crom, W. 1988/1989. La interpretación geográfica de fuentes históricas: el ejemplo del valle de Azapa, Arica-Chile. Diálogo Andino 7/8:43-56.

Dauelsberg, P. 1972/1973. La cerámica de Arica y su situación cronológica. Chungara 1-2:17-24.

Drennan, R. 2008. Settlement System Analysis. En Encyclopedia of Archaeology, editado por D. Pearsall, pp. 1980-1982, Academic Press, San Diego and Oxford.

Espoueys, O. 1973. Archivo: Inventario de sitios arqueológicos en los valles de Arica. Oficina de Registro, Museo San Miguel de Azapa, Departamento de Antropología. Universidad de Tarapacá, Arica.

Fernández, M. e I. Muñoz 2015. Una contribución al estudio de la organización social de los Períodos Formativo y Medio: aplicación del análisis jerárquico y de la regla tamaño en los asentamientos del valle de Azapa. Actas del XIX Congreso Nacional de Arqueología Chilena, pp. 173-183. Universidad de Tarapacá, Sociedad Chilena de Arqueología, Arica.

Focacci, G. 1983. El Tiwanaku clásico en el valle de Azapa. En Asentamientos aldeanos en los valles costeros de Arica. Documento de Trabajo 3:94-113.

Goldstein, P. 1989. OMO, A Tiwanaku Provincial Center in Moquegua, Perú. Dissertation Ph.D. Department of Anthropology. The University of Chicago, Chicago.

Goldstein, P. 1993. House, Community and State in the Earliest Tiwanaku Colony: Domestic patterns and State. Integration at Omo M12, Moquegua. En Domestic Architecture, Ethnicity, and Complementarity in the South Central-Andes, editado por M.S. Aldenderfer, pp. 25-41. University of Iowa Press, Iowa City.

Goldstein, P. 1995-1996. Tiwanaku settlement patterns of the Azapa Valley. Diálogo Andino 14-15:57-73.

Goldstein, P. 1998. Moquegua y el Imperio Tiwanaku. En Moquegua, los Primeros Doce Mil Años, editado por K. Wise, traducido por M. Barrionuevo, pp. 45-58. Museo Contisuyo, Arequipa.

Goldstein, P. 2000. Communities without borders: The Vertical Archipelago and Diaspora Communities in the Southern Andes. En The Archaeology Communities: A New World Perspective, editado por J. Yaeger y M. Canuto, pp. 182-209. Routledge Press, London.

Goldstein, P. 2006. Andean Diaspora: The Tiwanaku Colonies and the Origins of South American Empire. University Press of Florida, Florida.

González, F., A. Riquelme, P. Contreras y P. Mazuela 2013. Antecedentes generales para la sustentabilidad de la producción hortícola en el valle de Azapa, Arica, Chile. Idesia 31:119-123.

Gordillo, J. 1993. Inventario, Catastro y Evaluación de Sitios Arqueológicos en el Valle Medio del Río Caplina, Tacna. Tesis Universitaria. Facultad de Ciencias Histórico-Arqueológicas. Universidad Católica "Santa María”, Arequipa. 
Gordillo, J. 1997. Tacna y el Período Formativo en los Andes Centro-Sur (1.000 a.C. - 500 d.C.). Revista Ciencia y Cultura 1. Ed. Consejo de Investigación (COIN) de la UNJBG, Tacna.

Gordillo, J. 2000. Desde Tiwanaku hasta la ocupación Inka en el valle medio del Río Caplina, Tacna-Perú. Cultura y Desarrollo 2:83-108.

Hidalgo, J. 2004. Pescadores del litoral árido de valles y quebradas del norte de Chile y su relación con agricultores, siglos XVI y XVII. En Historia Andina en Chile, editado por J. Hidalgo, pp. 431-470. Editorial Universitaria, Santiago.

Hodder, I. y C. Orton 1990. Análisis Espacial en Arqueología. Editorial Crítica, Barcelona.

Keller, C. 1946. El Departamento de Arica. Vol. I. Censo Económico Nacional, Santiago.

Korpisaari, A. 2006. Death in the Bolivian High Plateau. Buriales and Tiwanaku Society. BAR Internacional Series 1536, Oxford.

Ledezma, M. 2010. Área de Captación de Recursos Vegetales del Tumulo 1 - Sitio Az-67 - Período Formativo, Valle de Azapa, Arica-Chile. Memoria para optar al grado de Licenciatura en Arqueología, Universidad de Tarapacá, Arica.

Lumbreras, L. 1974. La Arqueología Como Ciencia Social. Ediciones Histar, Lima.

Mathews, J. 2003. Prehistoric settlement patterns in the Middle Tiwanaku Valley. En Tiwanaku and Its Hinterland. Archaeology and Paleoecology of and Andean Civilization, editado por A.L. Kolata, pp. 112-128, Smithsonian Institution Press, Washington, D.C.

McAndrews, T., J. Albarracín-Jordán y M. Bermann 1997. Regional Settlement Patterns in the Tiwanaku Valley of Bolivia. Journal of Field Archaeology 24:67-83.

Mujica, E., M. Rivera y T. Lynch 1983. Proyecto de estudio sobre la complementariedad económica Tiwanaku en los valles accidentales del centro-sur andino. Chungara 11:85-109.

Muñoz, I. 1982. Dinámica de las Estructuras Habitacionales en el extremo Norte de Chile (Valle-Costa). Chungara 8:3-32.

Muñoz, I. 1983. El poblamiento aldeano en el valle de Azapa y su vinculación con Tiwanaku (Arica-Chile). Documento de Trabajo 3:43-93. Universidad de Tarapacá, Arica.

Muñoz, I. 1993. Spatial dimensions of complementary resource utilization at Acha 2 and San Lorenzo. En Domestic Architecture, Ethnicity and Complementary in the South Central Andes, editado por M. Aldenderfer, pp. 94:102. Iowa press, Iowa.

Muñoz, I. 1995/1996. Poblamiento humano y relaciones interculturales en el valle de Azapa: Nuevos hallazgos en torno al Período Formativo y Tiwanaku. Diálogo Andino 14-15:241-278.

Muñoz, I. 2004a. Estrategias de Organización Prehispánicas en Azapa: El Impacto de la Agricultura en un Valle del Desierto Costero. Ediciones Universidad de Tarapacá, Arica.

Muñoz, I. 2004b. Ocupación del espacio doméstico y áreas de actividad generadas en el asentamiento prehispánico de San Lorenzo. Diálogo Andino 24-53-98.

Muñoz, I. 2005. Espacio social y áreas de actividad en asentamientos agrícolas prehispánicos tardíos en la sierra de Arica. Bulletin de I'Institut Francais d'Ëtudes Andines 34:321-355.
Muñoz, I. 2015. Una aproximación a la organización territorial en el valle de Azapa durante la fase final del Período Formativo y comienzos del Período Medio, norte de Chile. Actas del XIX Congreso Nacional de Arqueología Chilena, pp. 201-212.

Muñoz, I. y J. Chacama 2006. Complejidad Social en las alturas de Arica: Territorio, Etnicidad y Vinculación con el Estado Inca. Ediciones Universidad de Tarapacá, Santiago.

Muñoz, I. y G. Focacci 1985. San Lorenzo: Testimonio de una comunidad de agricultores y pescadores Tiwanaku en el valle de Azapa (Arica-Chile). Chungara 15:7-30.

Muñoz, I y F. Zalaquett 2011. El paisaje en la distribución de los túmulos funerarios del valle de Azapa, durante el Período Formativo, norte de Chile. Revista de Geografía Norte Grande 50:23-43.

Niemeyer, H., V. Schiappacasse e I. Solimano 1972-1973. Patrones de poblamiento en la quebrada de Camarones. Actas del VI Congreso Nacional de Arqueología Chilena pp. 115-138, Santiago.

Núñez, L. 1989. Hacia la producción de alimentos y la vida sedentaria (5.000 a.C. a 900 d.C.). En Prehistoria de Chile. Desde sus Orígenes Hasta los Albores de la Conquista, editado por J. Hidalgo, V. Schiappacasse, H. Niemeyer, C. Aldunatee e I. Solimano, pp. 81-106. Editorial Andrés Bello, Santiago.

Rivera, M. 1983. Patrones prehistóricos y contemporáneos del uso de la tierra en el valle de Azapa. Norte de Chile. Diálogo Andino 2:9-21.

Roper, D. 1979. Method and theory in the site catchments analysis: A review. En Advances in Archaeological Method and Theory, editado por M.B. Schiffer, Vol. 2, pp. 119-140. Academic Press, New York.

Salcedo, L. 1998. Una aproximación al Período Arcaico del área Central andina. Andesita 1(2):1-44.

Sanhueza, L., L. Cornejo y F. Falabella 2007. Patrones de asentamiento en el Período Alfarero Temprano de Chile Central. Chungara Revista de Antropología Chilena 39:103-115.

Schortman, E. y P. Urban 1985. Modeling interregional interaction in Prehistory. En Advances in Archaeological Method and Theory, editado por M. Schiffer, Vol 10, pp. 37-95. Academic Press, New York.

Tapia, A. 2014. Marco geográfico natural del valle de Azapa. En Mil Años de Historia de los Constructores de Túmulos de los Valles Desérticos de Arica: Paisaje, Monumentos y Memoria, editado por I. Muñoz y S. Fernández, pp. 23-38. Ediciones Universidad de Tarapacá, Arica.

Trimborn, H. 1975. Investigaciones arqueológicas en los valles de Caplina y Sama (Dpto. Tacna-Perú). Studia Institute Anthropos 25:171-178. Editorial Verbo Divino, Estella.

Uhle, M. 1919. La arqueología de Arica y Tacna. Boletín de la Sociedad Ecuatoriana de Estudios Históricos 3:1-48.

Urban, P., E. Schortman y M. Ausec 2002. Power without bounds? Middle Preclassic political development in the Naco Valley, Honduras. Latin American Antiquity 13:131-152.

Urbina, S., L. Adán, C. Moragas, S. Olmos y R. Ajata 2011. Arquitectura de asentamientos de la costa de Tarapacá, norte 
de Chile. Estudios Atacameños, Arqueología y Antropología Surandinas 41:63-96.

Uribe R., M., F. Santana-Sagredo, A. Maturana F., S. Flores C. y C. Agüero P. 2016. San Pedro de Atacama y la cuestión Tiwanaku en el Norte de Chile: impresiones a partir de un clásico estudio cerámico y la evidencia bioarqueológica actual (400-1.000 d.C.). Chungara Revista de Antropología Chilena 48:173-198.

Vásquez de Espinosa, A. 1948 [1629]. Compendio y Descripción de las Indias Occidentales. Transcrito del manuscrito original por Charles Upson Clark. Publ. 3898. Vol. 108. Smithsonian Institution, Washington, DC.
Watanabe, L. y Ch. Stanish 1990. Ocupaciones domésticas en el Período Tiwanaku Tardío, Otora-Moquegua. En Trabajos Arqueológicos en Moquegua, Perú, editado por L. Watanabe, M.E. Moseley y F. Cabieses, pp. 75-90. Editorial Escuela Nueva S.A., Lima.

Vela, C. 2002. El Apogeo de las Piedras. Una Aproximación a la Prehistoria de Tacna. Caja Municipal del Ahorro y Crédito de Tacna, Tacna.

Williams, P., J. Isla y D.J. Nash 2001. Cerro Baul: un enclave Wari en interacción con Tiwanaku. Boletín de Arqueología PUCP 5:69-87.

\section{Notas}

1 A la fecha las investigaciones sobre el período Medio se han centrado en el valle de Azapa. Recientes excavaciones realizadas por el arqueólogo Marco Portilla en Terraza Chinchorro, costa norte de Arica, están documentando algunos pisos de ocupación para este período.

2 Lumbreras (1974) y Salcedo (1998) entre otros, señalan que los campamentos corresponderían a núcleos de residencia tipo choza de carácter temporal, con un sistema constructivo de carácter básico, en cambio las aldeas, constituirían viviendas permanentes, las que pueden estar aglutinadas, en torno a un eje central o disperso, teniendo un espacio mayor que los une como los campos de cultivos, cementerios y espacios ceremoniales abiertos tipo plazas. El sistema constructivo de una aldea es más sólido, para nuestro caso serían estructuras de caña, levantadas sobre una terraza.

3 Hidalgo (2004) a través de la documentación histórica señala que en el sector medio del valle de Azapa, habría existido una gran laguna, que denominaban Ocurica, en cuyos alrededores habitaban poblaciones Camanchacas quienes cultivaban la tierra. Dicho pulmón verde, nutría de recursos de caza y recolección a la población del valle. Una situación similar, sugerimos, pudo ocurrir durante el desarrollo de la aldea de San Lorenzo. 
